\title{
The complement of protein kinases of the microsporidium Encephalitozoon cuniculi in relation to those of Saccharomyces cerevisiae and Schizosaccharomyces pombe Diego Miranda-Saavedra1,5, Michael JR Stark ${ }^{1}$, Jeremy C Packer², Christian P Vivares ${ }^{3}$, Christian Doerig*4 and Geoffrey J Barton*1
}

Address: ${ }^{1}$ College of Life Sciences, University of Dundee, Dow St, Dundee DD1 5EH, Scotland, UK, ${ }^{2}$ Division of Advanced Technologies, Abbott Laboratories, 100 Abbott Park Road, Abbott Park, IL 60064, USA, ${ }^{3}$ Laboratoire de Parasitologie Moléculaire et Cellulaire. UMR CNRS 6023, Université Blaise Pascal, Aubière, France, ${ }^{4}$ INSERM U609, Wellcome Centre for Molecular Parasitology, Glasgow Biomedical Research Centre, 120 University Place, Glasgow G12 8TA, Scotland, UK and ${ }^{5}$ Cambridge Institute for Medical Research, Wellcome Trust/MRC Building, Addenbrooke's Hospital, Hills Road, Cambridge CB2 OXY, UK

Email: Diego Miranda-Saavedra - diego@compbio.dundee.ac.uk; Michael JR Stark-m.j.r.stark@dundee.ac.uk; Jeremy C Packer - jeremy.packer@abbott.com; Christian P Vivares - christian.vivares@univ-bpclermont.fr; Christian Doerig* - cdoer001@udcf.gla.ac.uk; Geoffrey J Barton* - geoff@compbio.dundee.ac.uk

* Corresponding authors

This article is available from: http://www.biomedcentral.com/I47I-2/64/8/309

(c) 2007 Miranda-Saavedra et al; licensee BioMed Central Ltd.

This is an Open Access article distributed under the terms of the Creative Commons Attribution License (http://creativecommons.org/licenses/by/2.0), which permits unrestricted use, distribution, and reproduction in any medium, provided the original work is properly cited.

\begin{abstract}
Background: Microsporidia, parasitic fungi-related eukaryotes infecting many cell types in a wide range of animals (including humans), represent a serious health threat in immunocompromised patients. The $2.9 \mathrm{Mb}$ genome of the microsporidium Encephalitozoon cuniculi is the smallest known of any eukaryote. Eukaryotic protein kinases are a large superfamily of enzymes with crucial roles in most cellular processes, and therefore represent potential drug targets. We report here an exhaustive analysis of the $E$. cuniculi genomic database aimed at identifying and classifying all protein kinases of this organism with reference to the kinomes of two highly-divergent yeast species, Saccharomyces cerevisiae and Schizosaccharomyces pombe.
\end{abstract}

Results: A database search with a multi-level protein kinase family hidden Markov model library led to the identification of 29 conventional protein kinase sequences in the $E$. cuniculi genome, as well as 3 genes encoding atypical protein kinases. The microsporidian kinome presents striking differences from those of other eukaryotes, and this minimal kinome underscores the importance of conserved protein kinases involved in essential cellular processes. $\sim 30 \%$ of its kinases are predicted to regulate cell cycle progression while another $\sim 28 \%$ have no identifiable homologues in model eukaryotes and are likely to reflect parasitic adaptations. $E$. cuniculi lacks MAP kinase cascades and almost all protein kinases that are involved in stress responses, ion homeostasis and nutrient signalling in the model fungi $S$. cerevisiae and S. pombe, including AMPactivated protein kinase (Snfl), previously thought to be ubiquitous in eukaryotes. A detailed database search and phylogenetic analysis of the kinomes of the two model fungi showed that the degree of homology between their kinomes of $\sim 85 \%$ is much higher than that previously reported.

Conclusion: The E. cuniculi kinome is by far the smallest eukaryotic kinome characterised to date. The difficulty in assigning clear homology relationships for nine out of the twenty-nine microsporidian conventional protein kinases despite its compact genome reflects the phylogenetic 
distance between microsporidia and other eukaryotes. Indeed, the $E$. cuniculi genome presents a high proportion of genes in which evolution has been accelerated by up to four-fold. There are no orthologues of the protein kinases that constitute MAP kinase pathways and many other protein kinases with roles in nutrient signalling are absent from the $E$. cuniculi kinome. However, orthologous kinases can nonetheless be identified that correspond to members of the yeast kinomes with roles in some of the most fundamental cellular processes. For example, E. cuniculi has clear orthologues of virtually all the major conserved protein kinases that regulate the core cell cycle machinery (Aurora, Polo, DDK, CDK and Chkl). A comprehensive comparison of the homology relationships between the budding and fission yeast kinomes indicates that, despite an estimated 800 million years of independent evolution, the two model fungi share $\sim 85 \%$ of their protein kinases. This will facilitate the annotation of many of the as yet uncharacterised fission yeast kinases, and also those of novel fungal genomes.

\section{Background}

The microsporidian Encephalitozoon cuniculi is a small spore-forming unicellular eukaryote leading an obligate intracellular parasitic lifestyle [1]. Inside a parasitophorous vacuole, the life cycle comprises three major phases: invasion with a polar tube system, proliferation with binary fission (merogony), and spore differentiation. Mitosis is of the closed type and dense structures called 'spindle pole bodies' resemble those of yeast. Chitin, a major polysaccharide of the fungal cell wall, is present in the inner part of the microsporidian spore wall. Trehalose, a disaccharide frequently found in fungi, has also been detected in microsporidia. The parasite's infections have medical importance since its hosts include various mammals, including humans, where it is known to cause digestive and clinical syndromes affecting the nervous system in HIV-infected or cyclosporine-treated patients [1].

The small and compact 2.9 Mb genome of E. cuniculi has recently been sequenced and characterised [2,3]. It split into 11 linear chromosomes harbouring 1,997 proteincoding sequences in a tightly clustered configuration. This degree of compaction has been achieved partly by reducing rDNA sequences as well as many protein-coding genes and intergenic regions [3]. E. cuniculi is therefore a microbial eukaryote that is highly-adapted to its parasitic lifestyle, and its genome sequence provides an opportunity for cataloguing the proteins that constitute its signal transduction networks. This understanding should shed light into the molecular mechanisms of pathogenicity and, from a wider perspective, on the minimal protein kinasebased signal transduction requirements of a eukaryotic intracellular parasite.

Reversible protein phosphorylation plays a central role in most cellular processes (in eukaryotic cells 30\% of proteins carry phosphate groups, $[4,5])$. Deregulation of protein phosphorylation is at the origin of several pathologies (e.g. cancers and neurodegenerative diseases) and protein kinases are now considered promising drug targets [see e.g. [6,7]]. Indeed, the first kinase inhibitors to be developed as drugs have recently been made available on the market $[8,9]$.

The currently accepted classification of protein kinases splits the protein kinase superfamily into 'conventional' protein kinases (ePKs) and 'atypical' protein kinases (aPKs). ePKs are the largest group and have been sub-classified into 8 families by examining sequence similarity between catalytic domains, the presence of accessory domains, and by considering modes of regulation $[10,11]$. The $8 \mathrm{ePK}$ families are: the AGC family (including cyclic-nucleotide and calcium-phospholipid-dependent kinases, ribosomal S6-phosphorylating kinases, Gproteincoupled kinases, and all close relatives of these groups); the CAMKs (calmodulin-regulated kinases); the CK1 family (casein kinase 1, and close relatives); the CMGC family (including cyclin-dependent kinases, mitogen-activated protein kinases, glycogen synthase kinases [GSK3], and CDK-like kinases [CKLs]); the RGC family (receptor guanylate cyclase, which are similar in domain sequence to tyrosine kinases); the STE family (including many kinases functioning in MAP kinase cascades); the TK family (tyrosine kinases); and the TKL family (tyrosine kinase-like kinases). A ninth group, called the 'Other' group, consists of a mixed collection of kinases that could not be classified easily into the previous ePK families. The aPKs are a small set of protein kinases that do not share clear sequence similarity with $\mathrm{ePKs}$ but have been shown experimentally to have protein kinase activity [11], and comprise the following bona fide families [12]: Alpha (exemplified by myosin heavy chain kinase of Dictyostelium discoideum); PIKK (phosphatidyl inositol 3' kinaserelated kinases); PDHK (pyruvate dehydrogenase kinases); and RIO ('right open reading frame' as it was one of two adjacent genes that were found to be transcribed divergently from the same intergenic region [13]).

Protein kinases controlling the proliferation and development of parasitic eukaryotes represent attractive drug tar- 
gets, because (i) they are likely to be essential to parasite multiplication and/or development; and (ii) these enzymes display structural and functional divergence when compared to their mammalian counterparts, suggesting that specific inhibition can be achieved [14-16]. Furthermore, the importance of protein kinases in most crucial cellular processes makes them interesting subjects of fundamental investigations into the cell biology of parasitic eukaryotes. The availability of the entire genome sequences of several parasites permits the study of their protein kinase complements (their 'kinomes'). Hence, two recent studies $[17,18]$ reported the characterisation of the kinomes of the malaria parasite Plasmodium-falciparum, showing that this organism possesses 85 (or 99, depending on the criteria used in the two studies) conventional protein kinases. A more recent and comparative study of the kinomes of all Apicomplexa species whose genome sequence is available has found the number of proteins kinases for the P. falciparum kinome to be $87 \mathrm{ePKs}$ and 3aPKs (Miranda-Saavedra, D. et al, manuscript submitted). The published kinomes of the Trypanosomatid species Leishmaniamajor, Trypanosoma brucei and Trypanosoma cruzi indicate that these parasites harbour between 176 (T. brucei) and 199 (L. major) kinases, most of which are orthologous across the three Trypanosomatid species [19]. These kinomes compare to kinomes of 478, 115 and 106 conventional protein kinases in human, fission yeast and budding yeast, respectively $[11,20,21]$. Here, we present an analysis of the kinome of E. cuniculi, and show that this organism has the smallest characterised kinome of all eukaryotes examined to date.

\section{Results and discussion The kinome of E. cuniculi}

The 1,997 predicted peptides of E. cuniculi were scanned with a multi-level HMM library of the kinase catalytic domain. This library is especially sensitive for retrieving kinase catalytic domain sequences from databases and, at the same time, does an automatic classification of kinases into families [12]. The application of the HMM library retrieved 32 protein kinases in E. cuniculi (Table 1), two of which lacked critical residues that confer catalytic activity and which may therefore be pseudokinases [22]. The HMM library has also been shown to be selective enough to classify some kinases of the 'Other' group of $S$. cerevisiae into the main ePK families [12]. Among the ePKs, E. cuniculi was found to harbour 4 kinases of the AGC family, 5 CAMKs, 2 CK1s, 12 CMGCs, 1 TKL, and 5 kinases which, by complete clustering analysis with the kinomes of $S$. cerevisiae and S. pombe (see below), were found to belong to the 'Other' group. E. cuniculi was also found to encode 3 atypical protein kinases (aPKs): 2 of the PIKK family and one of the RIO family. No kinases of the ePK families RGC, TK, or FIKK (a family identified in P. falci- parum and apparently specific to Apicomplexa), or of the aPK families Alpha or PDHK, were found.

The largest protein kinase family in E. cuniculi was thus found to be the CMGC, most members of which are involved in the control of cell proliferation. The CMGC is also the largest family in Trypanosomatids [19], in P. falciparum [17], and in other Apicomplexa (Miranda-Saavedra, D. et al., submitted). Interestingly, no kinases of the STE or NIMA families were found, explaining the lack of success in amplifying microsporidian MAPK homologues by PCR (Thellier and Doerig, unpublished). It has been noted that $P$. falciparum also lacks canonical 3-component MAPKKK-MAKK-MAPK cascades [17]. The three Trypanosomatid species $L$. major, T. brucei and T. cruzi are known to possess kinases of the Ste7, Ste11, and Ste20 subfamilies [19]. Their kinomes are 2.5 times larger than that of $P$. falciparum, suggesting that MAP kinase cascades might have an ancestral origin, and which might have been lost in streamlined kinomes such as those of $E$. cuniculi or the malaria parasite.

TKLs have previously been found in Metazoa, Apicomplexan parasites, Entamoeba histolytica, and the plants Arabidopsis thaliana and Oryza sativa. These findings, together with the observation that the fungi Cryptococcus neoformans and Phanerochaetechrysosporium contain putative TKLs, suggests that TKLs have been lost secondarily from most fungal lineages [12]. Therefore, the finding of a putative TKL in E. cuniculi is not too surprising. The sole member of the TKL family in the microsporidian kinome represents the only instance of a protein kinase family found in E. cuniculi that is not represented in either S. cerevisiae or S. pombe (Table 1).

\section{The kinomes of S. cerevisiae and S. pombe and their homology relationships with the E. cuniculi kinome}

The kinome of $S$. cerevisiae was the first to be described [21], followed by those of several higher eukaryotic organisms published by the same group and now available through KinBase [23]. The budding yeast kinome consists of 115 conventional protein kinase (ePK) and 9 atypical protein kinase $(\mathrm{aPK})$ sequences. It has previously been noted that among the aPKs, there is evidence for protein phosphorylation activity only for members of the PIKK, PDHK, RIO, and Alpha families [12]. The kinome of $S$. pombe was described recently [20] as part of a study that incorporated the systematic deletion of each of the fission yeast kinases and analysis of the mutant phenotype. Bimbó et al. [20] identified 106 ePKs by interrogating public databases for sequences that had been annotated as kinases, but the aPKs were not considered. Computational analysis suggested that fission yeast contains no tyrosine kinases [20]. Thirty-one ePKs were considered as likely to have a 'tyrosine kinase signature' (although the 
Table I: The 32 protein kinases of $E$. cuniculi split by kinase family

\begin{tabular}{|c|c|c|c|c|}
\hline Kinase family & Protein Id & Size (amino acids) & UniProt & $\begin{array}{c}\text { Predicted Catalytic } \\
\text { Activity }\end{array}$ \\
\hline \multirow[t]{4}{*}{ AGC } & CAD25005.I & 871 & Q8SSJ0 & Active \\
\hline & CAD25568.I & 272 & Q8SRL5 & Active \\
\hline & CAD25584.I & 322 & Q8SRK8 & Active \\
\hline & CAD25776.I & 348 & Q8SR57 & Inactive $\left(K, D^{\prime}\right)$ \\
\hline \multirow[t]{5}{*}{ CAMK } & CAD26060.1 & 300 & Q8SQT4 & Active \\
\hline & CAD25086.I & 516 & Q8SSHI & Active \\
\hline & CAD26208.I & 414 & Q8SSA8 & Active \\
\hline & CAD26452.I & 467 & Q8SR98 & Active \\
\hline & CAD26242.1 & 566 & Q8SW3I & Active \\
\hline \multirow[t]{2}{*}{ CKI } & CAD26235.I & 327 & Q8SS96 & Active \\
\hline & CAD26108.I & 318 & Q8SQR2 & Active \\
\hline \multirow[t]{12}{*}{ CMGC } & CAD25082.I & 586 & Q8SSH4 & Active \\
\hline & CAD26483.I & 309 & Q8SR90 & Active \\
\hline & CAD25I74.I & 308 & Q8SW92 & Active \\
\hline & CAD2667I.I & 319 & Q8SRU0 & Active \\
\hline & CAD25660.I & 350 & Q8SRI3 & Active \\
\hline & CAD26328.I & 265 & Q8SRF5 & Active \\
\hline & CAD26006.I & 329 & Q8SQW2 & Active \\
\hline & CAD26495.I & 296 & Q8SR86 & Active \\
\hline & CAD26039.1 & 328 & Q8SQU8 & Active \\
\hline & CAD26498.I & 351 & Q8SR85 & Active \\
\hline & CAD2573I.I & 351 & Q8SR83 & Active \\
\hline & CAD25928.I & 405 & Q8SQZ4 & Active \\
\hline TKL & CAD26582.I & 694 & Q8SRY2 & Active \\
\hline \multirow[t]{5}{*}{ Other } & CAD26233.I & 454 & Q8SW35 & Active \\
\hline & CAD26466.I & 363 & Q8SR94 & Active \\
\hline & CAD24933.I & 488 & Q8SWM6 & Active \\
\hline & CAD26209.I & 390 & Q8SSA7 & Inactive $(K)$ \\
\hline & CAD25400.I & 185 & Q8SVD9 & Active \\
\hline \multirow[t]{2}{*}{ PIKK } & CAD25I42.I & 1935 & Q8SSE7 & \\
\hline & CAD25955.I & 1433 & Q8SQY7 & \\
\hline RIO & CAD26627.I & 409 & Q8SVI7 & \\
\hline
\end{tabular}

identity of this signature was not indicated) and 67/106 (63.2\%) ePKs were found to have direct homologues in $S$. cerevisiae as defined by mutual best-hit analysis. Deletion analysis of ePK genes indicated that $17 / 106 \mathrm{ePKs}(16 \%)$ are essential for cell viability. Of the remaining $89 \mathrm{ePKs}$, deletion phenotypes were assessed under various stress conditions. $46 \%$ of these non-essential ePKs of fission yeast were found to exhibit hypersensitivity to at least one of the 17 stress factors tested, allowing the functional grouping of fission yeast ePKs into 4 major signalling pathways according to the nature of the stress.

We have carried out an independent database search for ePKs and aPKs in $S$. pombe and have identified 3 additional ePKs, one of which is the fission yeast homologue of S. cerevisiae Bud32p (SPAP27G11.07: Table 2). Thus, the kinome of $S$. pombe was found to consist of $109 \mathrm{ePKs}$ and 8 aPKs (Table 2). Both the kinomes of S. cerevisiae and S. pombe lack kinases of the families RGC, TK, and Alpha. Phylogenetic analysis suggests that 91/109 (83.5\%) of ePKs of fission yeast share a homologue in S. cerevisiae; likewise $96 / 115(83.5 \%)$ of ePKs of $S$. cerevisiae have a homologue in $S$. pombe. With the inclusion of aPKs (i.e. considering the two complete kinomes) 100/117 (85.5\%) of $S$. pombe kinases have homologues in $S$. cerevisiae (Table 3). The same was found to be true for 104/124 $(83.9 \%)$ of S. cerevisiae kinases. Therefore, the degree of homology between the kinomes of the two fungi is $20 \%$ greater than previously reported [20]. Part of the improvement is because the multilevel HMM library produces an automatic classification of protein kinases into families. The advantage of doing family-family comparisons, and the subsequent generation of multiple alignments and phylogenetic analysis for each family, is that proteins that are closer sequence-wise make better alignments. Since a phylogenetic tree is only as good as the underlying alignment, splitting the kinases into families prior to generating phylogenies is a more powerful method for comparing entire kinomes. Since our analysis shows that there are up to 16 instances of potentially redundant paralogous ePK pairs in fission yeast (Table 3 ) it is likely that the proportion that are essential has been underestimated 
Table 2: The protein kinase complements of E. cuniculi, S. cerevisiae and S. pombe, split by family

\begin{tabular}{|c|c|c|c|c|c|c|c|c|}
\hline & \multicolumn{8}{|c|}{ ePKs } \\
\hline & AGC & CAMK & CKI & CMGC & STE & TKL & Other & Total \\
\hline EC & 4 & 5 & 2 & 12 & 0 & 1 & 5 & 29 \\
\hline SC & 20 & 37 & 4 & 25 & 14 & 0 & 15 & 115 \\
\hline \multirow[t]{3}{*}{ SP } & 20 & 28 & 5 & 26 & 13 & 0 & 17 & 109 \\
\hline & \multicolumn{5}{|c|}{ aPKs } & & & \\
\hline & PIKK & RIO & PDHK & Alpha & Total & & & \\
\hline EC & 2 & I & 0 & 0 & 3 & & & \\
\hline SC & 5 & 2 & 2 & 0 & 9 & & & \\
\hline SP & 5 & 2 & I & 0 & 8 & & & \\
\hline
\end{tabular}

if paralogue pairs that can complement each other's function are included, and the real value is probably over $20 \%$. Similar considerations in budding yeast also suggest that over $20 \%$ of protein kinase activities are essential for vegetative growth.

The establishment of homology relationships between the kinomes of $S$. cerevisiae and S. pombe (Table 3), together with additional information extracted from the Saccharomyces Genome Database [24,25] and Pombase $[26]$, sets a powerful scene for cross-annotating the kinomes of these model organisms and, by extension, of other fungal kinomes that will be characterised in the near future (Table 3). Homology relationships between the kinomes of $S$. cerevisiae, $S$. pombe and E. cuniculi will be discussed below on a family-by-family basis.

\section{AGC family}

E. cuniculi was found to harbour four AGC kinases (a family which includes cyclic-nucleotide and calcium-phospholipid-dependent kinases, ribosomal S6phosphorylating kinases, G protein-coupled kinases, and all close relatives of these groups), three of which have orthologues in the yeasts (Table 3, Fig. 1, Additional file 1). The previously characterised CAD25584.1 [27] is the microsporidian homologue of yeast PKA (encoded by $S$. cerevisiae TPK1-3) while CAD25568.1 is the homologue of the yeast Ipl1p/Ark1 Aurora kinases. PKA is universally found in eukaryotic cells and in both $S$. cerevisiae and $S$. pombe it is involved in nutrient sensing and signalling, sporulation and cellular stress responses [28-30]. Although this putative microsporidian PKA (CAD25584.1) is somewhat diverged from its yeast orthologues (Fig. 1), the identification of two PKA regulatory subunit homologues (CAD24891.1 and CAD25013.1) is consistent with the presence of PKA in E. cuniculi [27]. PKA has an essential function in budding yeast for vegetative growth [31] and is required in fission yeast for spore germination in response to glucose, but not for vegetative growth itself $[20,28]$. A major role of the $S$. cerevisiae Aurora kinase Ipl1p is to drive chromosome biorientation on the mitotic spindle by promoting detachment of kinetochores from microtubules when both sister chromatids are attached to microtubules from the same spindle pole $[32,33]$. The presence of an orthologue in E. cuniculi (CAD25568.1) and its binding partner Sli15 (CAD26983.1) suggests that this vital role is likely to be conserved in all eukaryotes, although Ipl1p, Ark1 and their mammalian homologues have additional cell cycle roles to play [34-37] that may also be important in the microsporidian.

Of the two remaining orphan E. cuniculi kinases in this group, one is predicted to be inactive (CAD25776.1; Table 1) while the second (CAD25005.1) clusters with yeast Cbk1p/Orb6 and Dbf2p/Dbf20p/Sid2 (Fig. 1). These yeast kinases are all essential (DBF2 and DBF20 are redundant and the gene knockouts show synthetic lethality in budding yeast:[38]) and share with CAD25005.1 a protein kinase $\mathrm{C}$ terminal domain (PF00433) that follows the protein kinase domain itself. Dbf2p and Dbf20p function in the budding yeast mitotic exit network (MEN) while fission yeast Sid2 is part of the analogous septation initiation network (SIN) in fission yeast $[39,40]$. However, since the Cdc15p/Cdc7 kinases that also function as essential components of these pathways are not present in E. cuniculi (see below), it is more likely that CAD25005.1 is functionally related to Cbk1p/Orb6. If E. cuniculi does lack a MEN/SIN pathway this may reflect a reduced need to coordinate cytokinesis with nuclear division, perhaps because the relative timing of these events is sufficient to ensure high fidelity division without specific mechanisms to coordinate them. In budding yeast the MEN is also critical for promoting inactivation of mitotic cyclin-dependent kinase activity (CDK) through release of the Cdc14p phosphatase from the nucleolus, but this role is not con- 
Table 3: Homology relationships between the kinomes of $S$. cerevisiae, $S$. pombe and $E$. cuniculi

\begin{tabular}{|c|c|c|c|c|}
\hline AGC family & & & & \\
\hline Sub-family & S. cerevisiae & S. pombe & E. cuniculi & Deletion mutant \\
\hline AKT & YPKI, YPK2 & SPCC24B 0.07 (gad8) & & Viable (Sc, Sp) \\
\hline AKT & $\mathrm{SCH} 9$ & SPACIB9.02c (sckl), SPAC22EI2.I4c (sck2) & & Viable (Sc, Sp) \\
\hline AUR & IPLI & SPCC320.I3c (arkl) & CAD25568.I & Lethal (Sc, Sp) \\
\hline BUB & BUBI & SPCCI322.12c (bubl) & & Viable (Sc, Sp) \\
\hline NDR & RIMI5 & SPAPBI8E9.02c (ppk I8), SPCCI450.I Ic (cekl) & & Viable (Sc, Sp) \\
\hline NDR & CBKI & SPAC82I.I2 (orb6) & CAD25005.I & Lethal (Sc, Sp) \\
\hline NDR & DBF2, DBF20 & SPCC4I7.06c (ppk35), SPAC24BII.II Ic (sid2) & & Lethal (sid2) \\
\hline PDKI & PKHI, PKH2 & SPCC576.15c (ksgl) & & Lethal $(k s g l)$ \\
\hline PDKI & YDR466W (PKH3) & SPBCI778.10c (ppk2I) & & Viable (Sc, Sp) \\
\hline PKA & TPKI, TPK2, TPK3 & SPBCI06.10 (pkal) & CAD25584.I & Viable (Sc, Sp) \\
\hline PKC & $\mathrm{PKCl}$ & SPACI7G8.I4c (pckl), SPBCI2DI2.04c (pck2) & & Lethal $(P K C I)$ \\
\hline RSK & KIN82 & SPBCI86I.09 (ppk22) & & Viable (Sc, Sp) \\
\hline RSK & YNR047W & SPAC4G8.05 (ppk/4) & & Viable (Sc, Sp) \\
\hline \multirow[t]{4}{*}{ RSK } & YBR028C & SPCC4G3.08 (pskl) & & Viable (Sc, Sp) \\
\hline & AGC unpaired & AGC unpaired & AGC unpaired & \\
\hline & YKLI7IW & SPBC725.06c (ppk3I) & CAD25776.1 & \\
\hline & & SPCCI62.10 (cmk2) & & \\
\hline
\end{tabular}

\section{CAMK family}

\begin{tabular}{|c|c|c|c|c|}
\hline Sub-family & S. cerevisiae & S. pombe & E. cuniculi & Deletion mutant \\
\hline CAMKI & CMKI, CMK2 & SPACUNKI2.02c $(\mathrm{cmkl})$ & & Viable (Sc, Sp) \\
\hline CAMKI & $R C K I, R C K 2$ & SPAC23AI.06c (cmk2), SPCCI322.08 (srkl) & & Viable (Sc, Sp) \\
\hline CAMKK & TOS3, PAKI & SPCC297.03 (sspl), SPCC1919.0I (ppk34) & & Viable (Sc, Sp) \\
\hline CAMKL & CHKI & SPCCI259.13 (chkl) & CAD26208.I & Viable (Sc, Sp) \\
\hline CAMKL & KINI, KIN2 & SPBC4F6.06 (kinl), SPBC32CI2.03c (ppk25) & $\begin{array}{l}\text { CAD26242.I, } \\
\text { CAD26452.I }\end{array}$ & Viable (Sc, Sp) \\
\hline CAMKL & KIN4, YPLI4IC & SPACII0.0I (ppkl) & & Viable (Sc, Sp) \\
\hline CAMKL & YPLI50W & SPAC890.03 (ppk/6) & & Viable (Sc, Sp) \\
\hline CAMKL & FUN3I, YOLO45W & SPACI805.01c (ppk6) & & Viable (Sc, Sp) \\
\hline CAMKL & SNFI & SPCC74.03c (ssp2), SPAC23H4.02 (ppk9) & & Viable (Sc, Sp) \\
\hline CAMKL & KCC4, GIN4, HSLI & SPAC644.06c (cdrl), SPAC57AI0.02 (cdr2) & & Viable (Sc, Sp) \\
\hline CAMK-Unique & MEKI & SPACI 4C4.03 (mekl) & & Viable (Sc, Sp) \\
\hline CAMK-Unique & PRRI & SPBC337.04 (ppk27) & & Viable (Sc, Sp) \\
\hline $\mathrm{HAL}$ & SAT4 & SPAC29A4.16 (ppkl0) & & Viable (Sc, Sp) \\
\hline HAL & YOR267C, YDL025C & SPCCI020.10 (oca2) & & Viable (Sc, Sp) \\
\hline RAD53 & RAD53 & SPCCI8B5.IIc (cdsI) & & Lethal (RAD53) \\
\hline RAN & KSPI & SPBCI6E9.13 (ppk20) & & Viable (Sc, Sp) \\
\hline \multirow[t]{10}{*}{ ULK } & APGI & SPCC 63.08c $(p p k 36)$ & & Viable (Sc, Sp) \\
\hline & CAMK unpaired & CAMK unpaired & $\begin{array}{l}\text { CAMK } \\
\text { unpaired }\end{array}$ & \\
\hline & (PTKI, PTK2) & SPAC22G7.08 (ppk8) & CAD26060.1 & \\
\hline & (HAL5, KKQ8) & (SPCC70.05c (ppk37, Lethal), SPBC2I.07c (ppk24)) & CAD25086.I & \\
\hline & DUNI & SPBC19C2.05 & & \\
\hline & YMR29IW & SPACI5A 10.13 & & \\
\hline & (NPRI, PRR2) & SPBP23A 10.10 & & \\
\hline & IKSI & & & \\
\hline & YGR052W & & & \\
\hline & ISRI & & & \\
\hline
\end{tabular}

\section{CKI family}


Table 3: Homology relationships between the kinomes of S. cerevisiae, S. pombe and E. cuniculi (Continued)

\begin{tabular}{|c|c|c|c|c|}
\hline CKI & YCKI & SPACI805.05 (cki3) & & \\
\hline CKI & YCK2 & SPBCI347.06c (ckil) & & \\
\hline CKI & YCK3 & SPBP35G2.05c (cki2) & & \\
\hline \multirow[t]{2}{*}{ CKI } & HRR25 & SPBC3H7.I5 (hhpl) & CAD26235.I & Lethal (HRR25) \\
\hline & & SPAC23C4.12 (hhp2) & CAD26108.I & \\
\hline \multicolumn{5}{|c|}{ CMGC family } \\
\hline Sub-family & S. cerevisiae & S. pombe & E. cuniculi & Deletion mutant \\
\hline CDC7 & CDC7 & SPBC776.I2c (hskl), SPBC2IC3.I8 (spo4) & $\begin{array}{l}\text { CAD26498.1, } \\
\text { CAD25731.I }\end{array}$ & Lethal $(C D C 7, h s k l)$ \\
\hline CDK & KIN28 & SPBCI9F8.07 (crkl) & CAD25I74.I & Lethal $(K I N 28, c r k I)$ \\
\hline CDK & $C D C 28$ & SPBCIIBI0.09 (cdc2) & CAD26495.I & Lethal $(C D C 28, c d c 2)$ \\
\hline CDK & CTKI & SPAC2F3.I5 (lskl) & CAD26006.I & Viable (Sc, Sp) \\
\hline CDK & CAKI & SPACID4.06c (cskl) & & Lethal $(C A K I)$ \\
\hline CDK & SGVI & SPBC32H8.10 (cdk9) & & Lethal (SGVI, cdk9) \\
\hline CDK & $\mathrm{PHO85}$ & SPCCI6C4.II (pefl) & & Viable (Sc, Sp) \\
\hline CDK & SSN3 & SPAC23H4.I7c (srb/0) & & Viable (Sc, Sp) \\
\hline CK2 & CKAI, CKA2 & SPAC23CII.II (ckal) & CAD2667I.I & Lethal (ckal) \\
\hline CLK & KNSI & SPACID4.IIc (lkhl) & & Viable (Sc, Sp) \\
\hline DYRK & YAKI & SPAC823.03 $(p p k / 5)$ & CAD25928.I & Viable (Sc, Sp) \\
\hline GSK & RIMII, MRKI & SPBC8D2.0I (gsk3l), SPACI687.I5 (gsk3) & & Viable (Sc, Sp) \\
\hline MAPK & FUS3, KSSI & SPAC3IG5.09c (spkl) & & Viable (Sc, Sp) \\
\hline MAPK & HOGI & SPAC24BI I.06c (styl) & & Viable (Sc, Sp) \\
\hline MAPK & SLT2, YKLI6IC & SPBCII9.08 (pmkl) & & Viable (Sc, Sp) \\
\hline RCK & IME2 & SPAC3C7.06c (pit l), SPBC8D2.19 (mde3) & & Viable (Sc, Sp) \\
\hline SRPK & SKYI & SPBC530.14c (dskl) & & Viable (Sc, Sp) \\
\hline \multirow[t]{6}{*}{ TTK } & MPSI & SPBCI06.0I (mphl) & CAD25082.I & Lethal (MPSI) \\
\hline & CMGC unpaired & CMGC unpaired & $\begin{array}{l}\text { CMGC } \\
\text { unpaired }\end{array}$ & \\
\hline & SMKI & SPACI6C9.07 (ppk5), SPAC2F7.03c (poml) & CAD25660.1 & \\
\hline & (MCKI, YOLI28C) & SPCC777.I4 (prp4, Lethal) & $\begin{array}{l}\text { (CAD26039.1, } \\
\text { CAD26483.I) }\end{array}$ & \\
\hline & & SPBC336.14C & & \\
\hline & & SPBCI8HI0.I5 (ppk23) & CAD26328.I & \\
\hline
\end{tabular}

\begin{tabular}{|c|c|c|c|c|}
\hline \multicolumn{5}{|l|}{ STE family } \\
\hline Sub-family & S. cerevisiae & S. pombe & E. cuniculi & Deletion mutant \\
\hline STE7 & PBS2 & SPBC409.07c (wis I) & (none) & Viable (Sc, Sp) \\
\hline STE7 & MKKI, MKK2 & SPBC543.07 (pekl) & & Viable (Sc, Sp) \\
\hline STE7 & STE7 & SPACID4.I3 (byrl) & & Viable (Sc, Sp) \\
\hline STE20 & STE20 & SPBCI604.I4c (shkl) & & Lethal $(s h k l)$ \\
\hline STE20 & CLA4, SKMI & SPACIF5.09c (shk2) & & Viable (Sc, Sp) \\
\hline STE20 & SPSI & SPAC2C4.I4c (ppkll), SPAC9GI.09 (sidl) & & Lethal (sidI) \\
\hline STE20 & $\mathrm{CDCl}$ & SPBC2I.06c $(c d c 7)$ & & Lethal $(C D C \mid 5, c d c 7)$ \\
\hline STE20 & $\mathrm{KICl}$ & SPBCI7F3.02 (nakl) & & Lethal $(\mathrm{KICl}$, nakl) \\
\hline STEII & SSK2, SSK22 & SPACI006.09 (winl), SPAC9GI.02 (wis4) & & Viable (Sc, Sp) \\
\hline STEII & STEII & SPBCID7.05 (byr2) & & Viable (Sc, Sp) \\
\hline STEII & $B C K I$ & SPACIF3.02c $(m k h l)$ & & Viable (Sc, Sp) \\
\hline
\end{tabular}

\section{Other group}

\begin{tabular}{llll}
\hline Sub-family S. cerevisiae & S. pombe & E. cuniculi & Deletion mutant
\end{tabular}


Table 3: Homology relationships between the kinomes of S. cerevisiae, S. pombe and E. cuniculi (Continued)

\begin{tabular}{|c|c|c|c|c|}
\hline Bud32 & BUD32 & SPAP27G11.07c\$\$ & CAD25400.I & Viable (BUD32) \\
\hline GCN2 & GCN2 & SPAC20G4.03c (hril) & & Viable (Sc, Sp) \\
\hline IRE & IREI & SPACI67.0I (ppk4) & & Viable (Sc, Sp) \\
\hline NAK & YPL236C & SPAC $3 \mathrm{HI} .13(p p k / 3)$ & & Viable (Sc, Sp) \\
\hline NAK & $A K L I, P R K I, A R K I$ & $\begin{array}{l}\text { SPCPIEIII.02 (ppk38), SPBC6BI.02 (ppk30), SPBC557.04 } \\
(p p k 29)\end{array}$ & & Viable (Sc, Sp) \\
\hline NEK & KIN3 & SPACI9E9.02 (finl) & & Viable (Sc, Sp) \\
\hline PLK & CDC5 & SPAC23CII.16 (plol) & CAD24933.I & Lethal $(C D C 5$, plol $)$ \\
\hline VPSI5 & VPSI5 & SPBCII 9.07 (ppk/9) & & Viable (Sc, Sp) \\
\hline \multirow[t]{7}{*}{ WEE } & SWEI & SPCCI8B5.03 (weel), SPBC660.I4 (mikl) & CAD26466.I & Viable (Sc, Sp) \\
\hline & Other unpaired & Other unpaired & Other unpaired & \\
\hline & SCYI & $S P B C I 5 C 4.02 \$ \$$ & CAD26209.1 & \\
\hline & ELMI & SPACI2BI0.I4c (ppk2) & CAD26233.I & \\
\hline & & SPAC23C4.03\$\$ & & \\
\hline & & SPAC222.07c (hri2) & & \\
\hline & & SPBC36B7.09 (ppk28) & & \\
\hline \multirow[t]{2}{*}{ TKL family } & S. cerevisiae & S. pombe & E. cuniculi & Deletion mutant \\
\hline & (none) & (none) & CAD26582.1 & Unknown \\
\hline \multirow[t]{6}{*}{ PIKK family } & S. cerevisiae & S. pombe & E. cuniculi & Deletion mutant \\
\hline & $\mathrm{MECl}$ & $S P B C 216.05$ & & \\
\hline & TELI & SPCC23B6.03C* & $\begin{array}{l}\text { CAD25I42.1, } \\
\text { CAD25955.I }\end{array}$ & \\
\hline & TORI & $S P B C 216.07 c$ & & \\
\hline & TOR2 & SPBC30D $10.10 \mathrm{C}$ & & \\
\hline & TRAI & SPACIF5.IIC & & \\
\hline \multirow[t]{3}{*}{ RIO family } & S. cerevisiae & S. pombe & E. cuniculi & \\
\hline & RIOI & SPACIOF6. 10 & & \\
\hline & $\mathrm{RIO2}$ & SPBCI 703.05 & CAD26627.I & \\
\hline \multirow[t]{3}{*}{ PDHK family } & S. cerevisiae & S. pombe & E. cuniculi & \\
\hline & YGL059W & & (none) & \\
\hline & YIL042C & SPAC644.IIC & & \\
\hline
\end{tabular}

$\$$ \$novel; no information on these $S$ pombe kinases

* SPAC22EI 2.16c, SPBC577.06c, and SPAC458.05 are TELI-related

served in fission yeast [41] and so may also not be vital in E. cuniculi. In budding yeast, Cbk1 is required for regulating cellular morphogenesis and the expression of genes involved in cell separation [42] and in fission yeast it may have an analogous role in coordinating morphogenesis and cell division [43]. These roles may therefore be highly conserved if CAD25005.1 is genuinely functionally related to these yeast kinases. However, CAD25005.1 also has a phorbol ester/diacylglycerol-binding C1 domain (PF00130) that is shared with yeast protein kinase Cs, although they are located at the opposite end of the polypeptide to their position in, for example, budding yeast Pkc1p, and there is no C2 domain (PF00168). Thus perhaps the most likely scenario is that CAD25005.1 represents a somewhat divergent PKC that, like its yeast counterparts, may be activated by Rho GTPases [44-47]. In budding yeast, Pkc1p is involved in promoting cell wall integrity [see [48]], an essential role that it shares with its fission yeast homologues [45].

Regarding the remaining AGC kinases present only in the two yeasts, almost all show direct homology relationships except for budding yeast YKL171W and fission yeast's ppk31 and ppk33, which appear to be lineage-specific 


\begin{tabular}{|l|}
\hline Bootstrap values \\
- $50 \%+$ \\
- $65 \%+$ \\
- $80 \%+$ \\
- $95 \%+$ \\
\hline
\end{tabular}

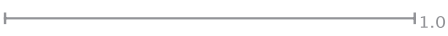

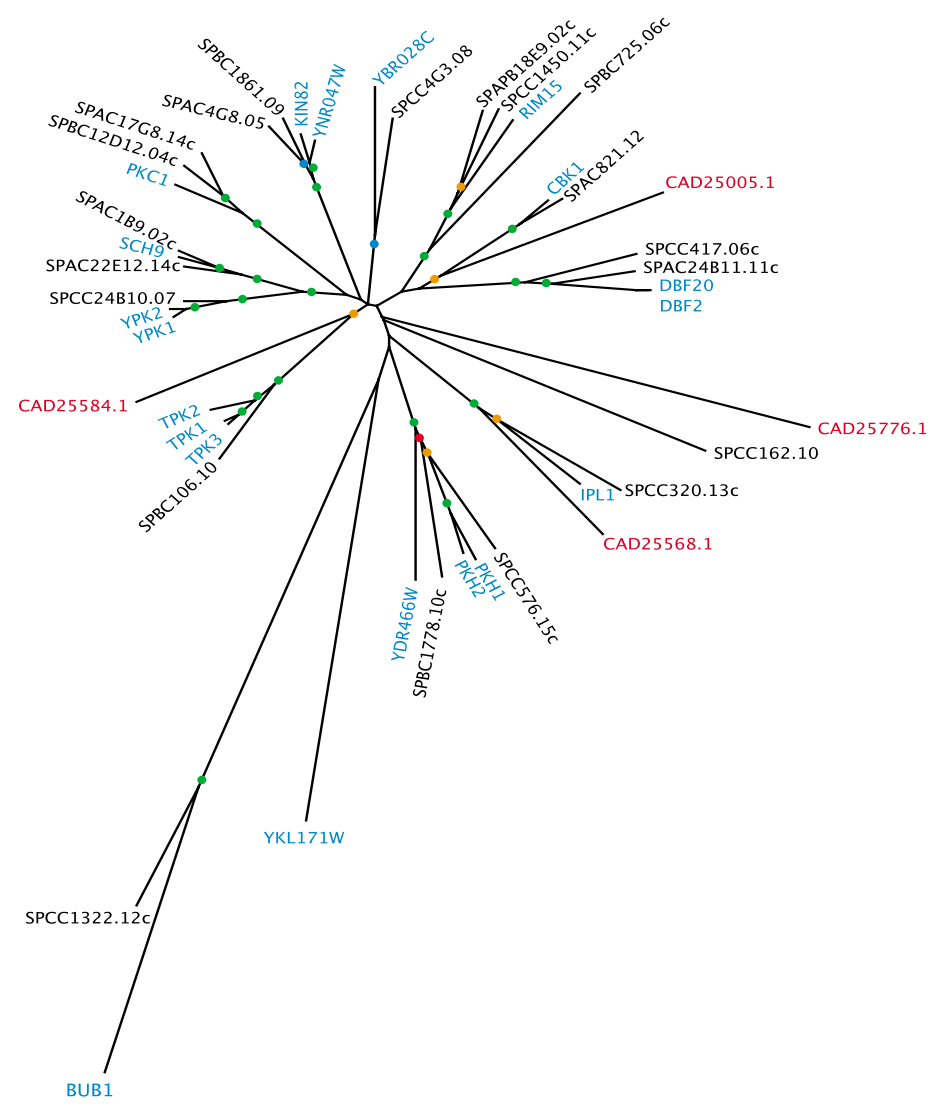

Figure I

Unrooted tree of the AGC kinases of S. cerevisiae (blue), S. pombe (black) and E. cuniculi (red).

(Table 3). Where the function of the conserved kinases is known, it frequently concerns nutrient signalling or cell integrity, functions that may be less important for an obligate intracellular parasite such as E. cuniculi. The PDK1 homologues are essential in both yeasts $[20,49,50]$, although the AKT homologues that should function downstream of the PDK1 homologues are essential only for vegetative growth in budding yeast [20]. Finally, since E. cuniculi lacks a homologue of the spindle checkpoint kinases Bub1p/Bub1 it is likely that this checkpoint mechanism is absent from the microsporidian. Although the spindle checkpoint is important in higher eukaryotes because of its role in the timing of mitotic events [see e.g. $[51,52]]$, it is non-essential in yeast under normal circumstances and is apparently dispensable in E. cuniculi.

\section{CAMK family}

Of the five CAMKs (calmodulin-regulated kinases) of $E$. cuniculi, only three could be shown to be homologues of yeast CAMKs, while the two other microsporidian CAMKs did not cluster with characterised fungal kinases within the same family ('semi-orphan'). CAD26208.1 is related to Chk1p/Chk1, while CAD26242.1 and CAD26452.1 are both related to Kin $1 \mathrm{p} / \mathrm{Kin} 2 \mathrm{p}$ of budding yeast and Kin1/ Ppk25 of fission yeast (Table 3, Fig. 2, Additional file 2). Given that budding yeast cells lacking both KIN1 and KIN2 are viable [53], finding two homologues of these kinases in E. cuniculi is surprising. In fission yeast, loss of just one of the two isoforms (Kin1p) produced a significant morphological defect [54], so perhaps simultaneous deletion of both isoforms will reveal a more critical role for this group of kinases in fission yeast. It also remains possible that a third budding yeast CAMK may function redundantly with Kin $1 \mathrm{p}$ and Kin2p. Budding yeast Kin $1 \mathrm{p}$ and Kin $2 \mathrm{p}$ are the homologues of C. elegans Par-1 [55], a protein kinase essential for the establishment of anteriorposterior polarity in the one-cell embryo and generally involved in the intracellular organisation cues in various biological systems. In E. cuniculi, the symmetric differentiation of the spore exhibits an evident anterio-posterior polarity and the Par-1 orthologue may have a role to play in this process. In fission yeast, loss of Kin 1 causes monopolar growth because cells fail to activate polarized growth at their new end (termed NETO for new end take- 
off: [55]). In S. cerevisiae, polarised growth takes the form of asymmetric growth of the bud and localized fusion of secretory vesicles at the bud tip in G1 cells until later in the cell cycle, when re-polarisation to the bud neck occurs. This is regulated both by changes in the actin cytoskeleton and in the distribution of the secretory landmark protein Sec3p, a component of the Exocyst complex [56]. It is therefore interesting that Kin $1 p$ and Kin $2 p$ interact with multiple components of the exocytic machinery and may regulate the fusion of secretory vesicles with the cell surface [57]. Thus taken together, these considerations point to a potential role of the E. cuniculi homologues in polarized secretion.

The E. cuniculi CAMK CAD26208.1 is the orthologue of Chk1 kinase in the yeasts (Table 3, Fig. 2). Although nonessential in both yeast species, this kinase nonetheless plays a central role in the DNA damage response, delaying mitosis to allow time for DNA repair to occur and stimulating the expression of DNA damage repair functions
[58]. In fact, in evolutionary terms Chk1 is considered the most ancient of the major cell cycle control kinases [59], which functions in a pathway downstream of a PIKK family member that is part of the damage sensing machinery [58]. The presence of a Mec1p/Tel1p-related PIKK kinase in E. cuniculi is therefore consistent with the presence of a Chk1 orthologue. Rad53p and Cds1 (orthologues of human Chk2 kinase) are also implicated in this checkpoint pathway, and are involved in stabilising stalled replication origins $[60,61]$. However, the relative importance of the Chk1 and Rad53p/Cds1/Chk2 arms for the response to DNA damage and stalled replication forks differs in different systems. Whereas Cds 1 and Rad53 are dispensable in fission yeast, Rad53p and Mec1p are essential in budding yeast because of an additional role in regulating dNTP levels $[62,63]$. Thus the single Chk1-related kinase in E. cuniculi may play roles in both the replication and repair aspects of this pathway.

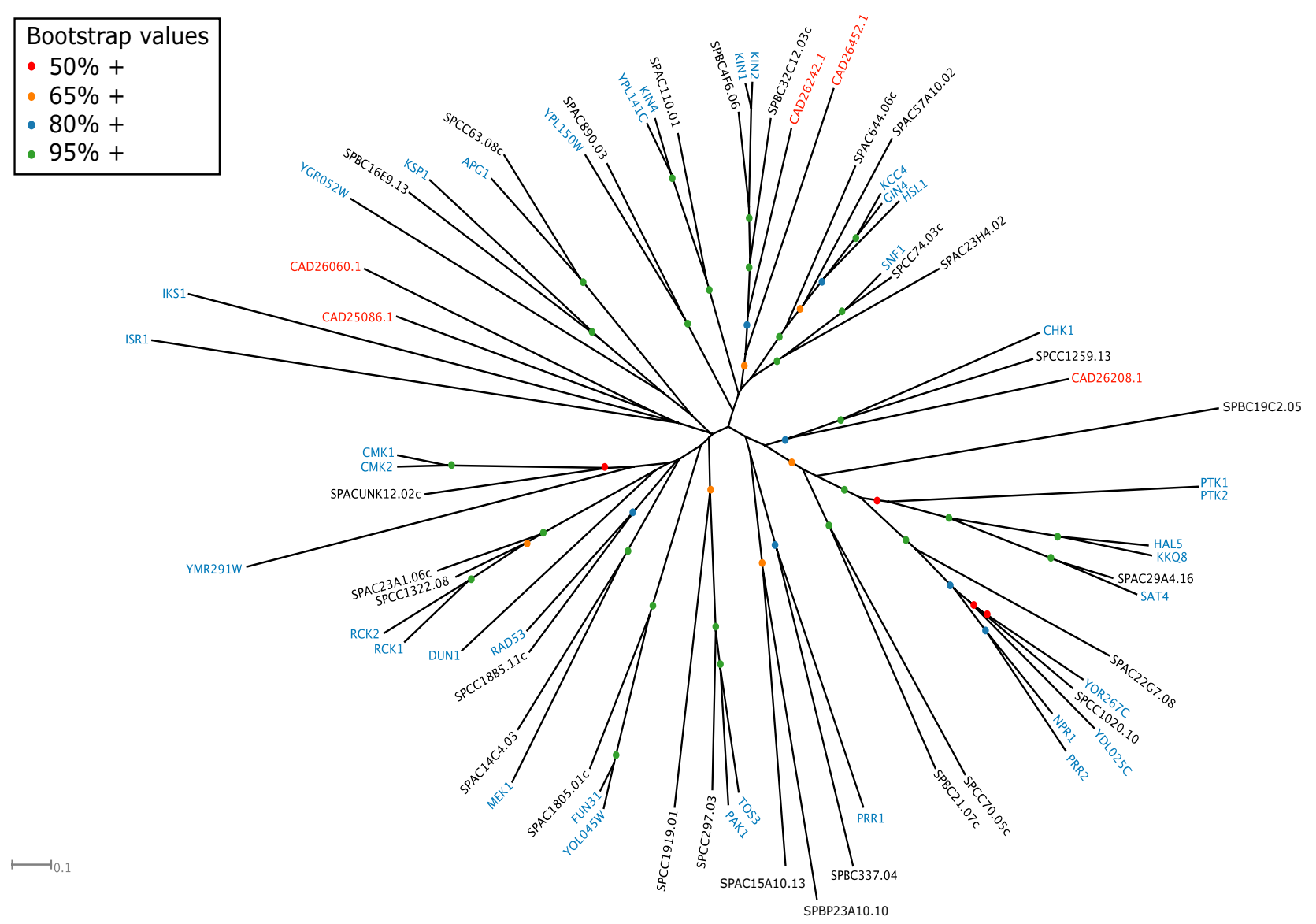

Figure 2

Unrooted tree of the CAMK kinases of S. cerevisiae (blue), S. pombe (black) and E. cuniculi (red). 
Perhaps the biggest surprise within this family of kinases is the apparent absence of an AMPK homologue (Snf1p in budding yeast), an enzyme previously thought to be ubiquitous in eukaryotes. All Apicomplexan genomes (Plasmodium ssp. falciparum, berghei, chabaudi and yoelii, Cryptosporidium ssp. hominis and parvum, Theileria ssp. annulata and parva, and Toxoplasma gondii) contain one AMPK orthologue (Miranda-Saavedra, D., et al., manuscript submitted), and E. cuniculi is therefore the first eukaryote to be described that lacks AMPK. AMPK has been termed the "fuel gauge of the cell", responding to the AMP/ATP ratio and downregulating ATP-consuming processes and upregulating ATP-generating processes in response to changing cellular energy balance [64]. In budding yeast, Snf1p has not been formally shown to be AMP regulated, but is critical for derepression of genes required for growth on non-fermentable carbon sources once glucose (and hence fermentative generation of ATP) has been exhausted [65]. In contrast, nothing is known about AMPK in fission yeast although it has two apparent orthologues. Consistent with the lack of an identifiable AMPK, E. cuniculi also lacks homologues of the protein kinases that are required to activate Snf1p (Tos3p, Pak1p and Elm1p, Table 3, [66]). Given that E. cuniculi has a limited ability to generate its own ATP and that it recruits host mitochondria close to its plasma membrane, it is likely that it imports host ATP using the four distinct ATP/ADP translocases that it encodes $[2,67]$. It may therefore have little capacity for controlling its energy balance except through ATP/ADP exchange with the host cell, and therefore effectively rely on regulation of host cell metabolism by the host cell's AMPK to ensure its own energy supply.

Budding yeast and fission yeast possess 11 and 6 lineagespecific CAMKs (i.e. with no identifiable orthologues in the other species: Table 3). The CAMKs not represented in E. cuniculi include budding yeast's Psk1p and Psk2p (FUN31 and YOL045W) (involved in nutrient sensing and metabolic regulation: [66]), Hrk1p (YOR267C) and Ptk2p (involved in plasma membrane ATPase regulation: [68]); Kcc4p/Gin4p/Hsl1p/Cdr1/Cdr2 (cell cycle regulators through phosphorylation of Swe1p/Wee1: $[69,70])$.

\section{CKI family}

The two microsporidian CK1s (casein kinase 1 and close relatives) cluster with the fungal homologues of Hrr25p (Table 3, Fig. 3, Additional file 3), and lack the C-terminal palmitoylation signal required for plasma membrane localization found in the three budding yeast Yck CK1 kinases $[71,72]$. Budding yeast Hrr25p is essential, as is the presence of at least one of the two redundant Yck1p and Yck2p isoforms [73]. Although the S. pombe Hhp1 and Hhp2 appear to be co-evolution paralogues of yeast Hhr25p, cells lacking both genes are viable [74]. CK1s in general and S. cerevisiae's Hrr25 in particular have been ascribed a wide range of functions [75] including vesicular trafficking, regulation of gene expression and DNA repair in yeast. One critical role in both yeast species is as part of a mechanism for ensuring monopolar attachment of sister kinetochores in meiosis I, a phenomenon that is essential for ensuring correct disjunction of maternal and paternal homologues [76]. However, since E. cuniculi is not thought to undergo meiosis, this role is unlikely to be important. Budding yeast Hrr25p is also an antagonist of calcineurin signalling by regulating the nuclear localisation and hence activity of the NFAT family transcription factor Crz1p [77]. This is a conserved $\mathrm{Ca}^{2+}$-signalling pathway that, amongst other processes, is involved in Tcell activation in mammals, although in $S$. cerevisiae it responds to a variety of environmental stresses that lead to elevated intracellular $\mathrm{Ca}^{2+}$, such as high salt and alkaline $\mathrm{pH}$. Further work will be required to determine whether either of these two critical roles are the focus of the $E$. cuniculi CK1 homologues.

\section{CMGC family}

The CMGCs (cyclin-dependent kinases, mitogen-activated protein kinases, glycogen synthase kinases [GSK3], and CDK-like kinases [CKLs]) are the largest family of kinases in the E. cuniculi genome and 8/12 microsporidian CMGCs can be assigned homology to a number of yeast CMGCs that play essential roles (Table 3, Fig. 4, Additional file 4). CAD26498.1 and CAD25731.1 are the microsporidian homologues of budding yeast Cdc7p, which has two paralogues in $S$. pombe, one of which (Hsk1) is also essential. These kinases are DDKs (Dbf4dependent kinases), so called because they are activated by binding to a regulatory subunit (Dbf4p in S. cerevisiae), and they play a fundamental role in the activation of licensed replication origins [78]. The other characterised microsporidian CMGCs are homologues of essential cyclin-dependent kinases such as Cdc28p/Cdc2 (CAD26495.1) and Kin28p/Crk1p (CAD25174.1), the homologue of yeast casein kinase II (CAD26671.1), the homologue of the dual-specificity kinase Yak1p (CAD25928.1), and the homologue of yeast TTK (Mps1p/ Mph1: CAD25082.1).

Of the cyclin-dependent kinases, Cdc28p/Cdc2 have clearly established fundamental roles in cell division, while the other yeast CDKs are involved in transcriptional regulation through modulating the phosphorylation state of the RNA pol II C-terminal domain (Ctk1p, Kin28p for example: see [29]). Thus although E. cuniculi does not show the full range of CDKs found in the yeasts, it nonetheless has homologues corresponding to both these classes, indicating that the roles of CDKs as cell cycle and RNA pol II regulators are presumably fundamental. Furthermore, at least two of the semi-orphan CMGC kinases (CAD26039.1 and CAD26328.1) may also belong to the 


\begin{tabular}{|l|}
\hline Bootstrap values \\
- $50 \%+$ \\
- $65 \%+$ \\
- $80 \%+$ \\
- $95 \%+$ \\
\hline
\end{tabular}

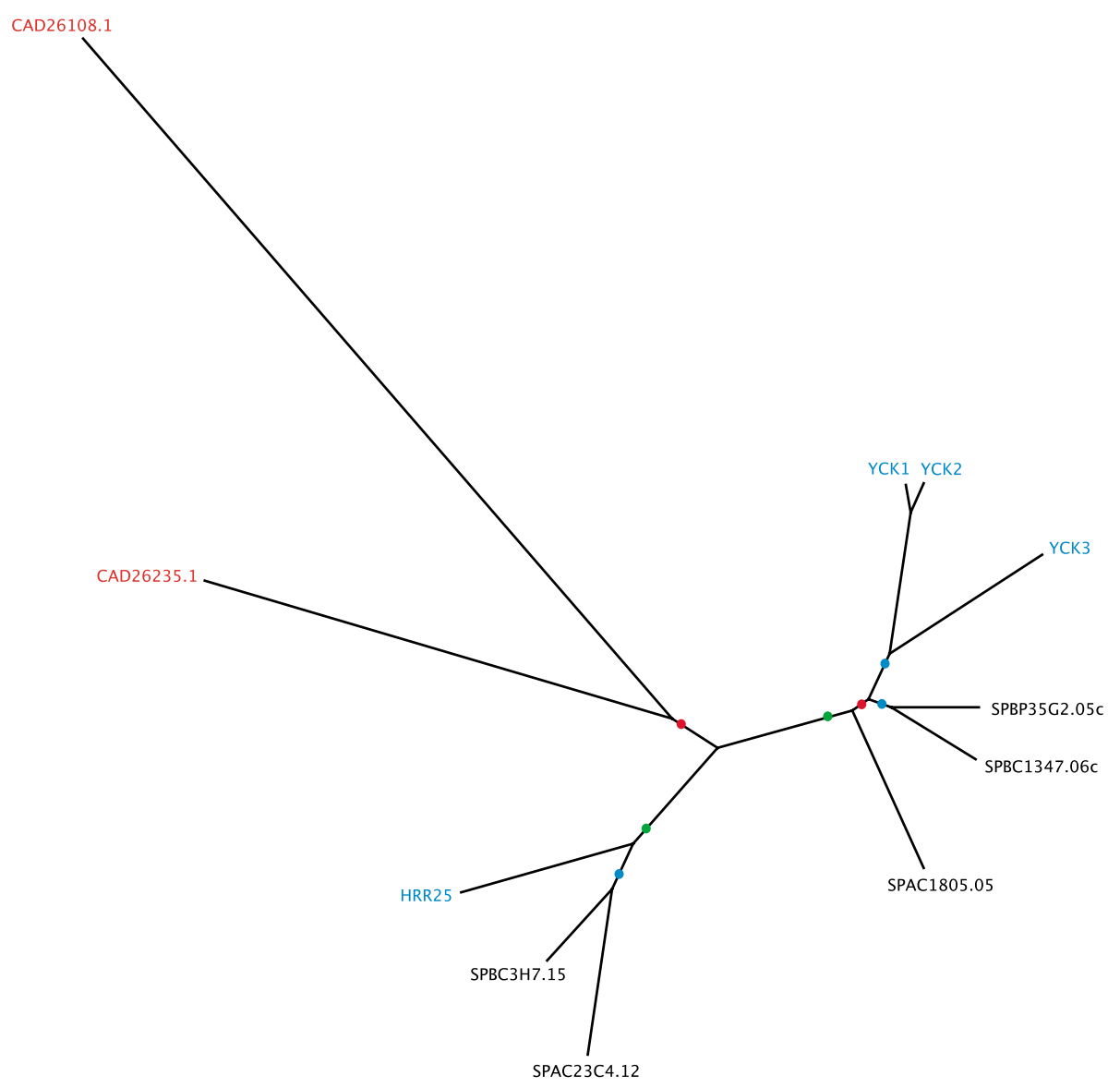

Figure 3

Unrooted tree of the CKI kinases of S. cerevisiae (blue), S. pombe (black) and E. cuniculi (red).

CDK group, although we have not classified them as such because they show considerable divergence from any of the conserved fungal CDKs. In common with many protein kinases, several CDKs require activatory phosphorylation on their Tloop threonine, which is carried out in budding yeast by Cak1p [79]. In metazoans, this role is carried out by Cyclin H-Cdk7 rather than by a single subunit Cak1p homologue. Both systems are present in fission yeast, although the Cak1p orthologue (Csk1) appears to be responsible for activating the Cdk7 orthologue (Crk1, also termed Mcs6), which is the direct CDK activator in vivo [80]. Since we have found an E. cuniculi orthologue of fission yeast Crk1 (CAD25174.1, Table 3), it is therefore likely that this Cdk7-related kinase is responsible for direct phosphorylation of its other CDKs and that there is no Cak1p-related kinase.

Both yeasts have a TTK member, which is known to play roles both in spindle pole duplication and in the spindle checkpoint response that monitors attachment of chro- mosomes to the mitotic spindle [81]. The spindle pole duplication role is conserved in mammals [82] although apparently not in fission yeast [83], and it is this function that makes MPS1 essential in S. cerevisiae. Since E. cuniculi lacks a Bub1p homologue (see above), another key kinase in the checkpoint pathway, it is likely that the microsporidian TTK (CAD25082.1) is involved primarily in spindle pole duplication.

Yeast Yak1p is a member of the conserved DYRK sub-family that is represented in fission yeast by the as yet uncharacterized Ppk15 (Table 3). Budding yeast Yap1p is involved in glucose signalling [84] and is associated with growth inhibition, functioning in an antagonistic manner either downstream of or in parallel with the PKA pathway $[85,86]$. The presence of a DYRK member in E. cuniculi is therefore consistent with the presence of a PKA orthologue and suggests that the functional relationship between PKA and DYRK has been conserved in the microsporidian. 


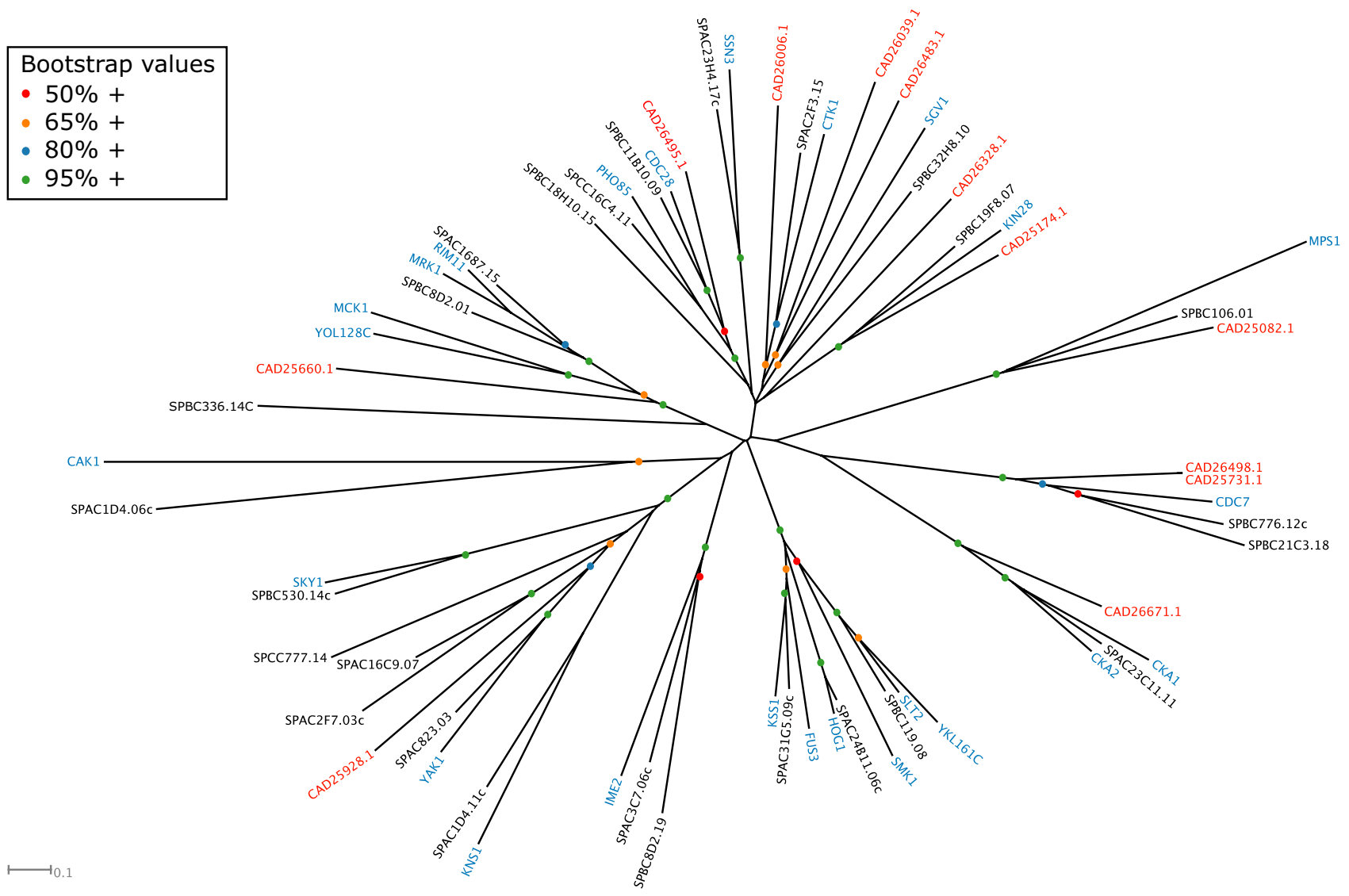

Figure 4

Unrooted tree of the CMGC kinases of S. cerevisiae (blue), S. pombe (black) and E. cuniculi (red).

Casein kinase II is a multifunctional enzyme with roles in processes as diverse as cell cycle progression, cell polarity and ion homeostasis $[87,88]$. The presence of an $E$. cuniculi orthologue (CAD26671.1) underlines the fundamental importance of this group of kinases and is consistent with the identification of a Casein Kinase II regulatory subunit (CAD25839.1).

Comparing the two model yeasts, most members of the CMGC family show orthologous relationships and there are few apparently lineage-specific 'semiorphans' (Table 3 ). Members of this family that are found in the yeasts but not the microsporidian include the MAP kinases (involved in stress-activated signal transduction pathways and mating: [89-92]), members of the RCK sub-group (involved in yeast meiotic regulation: $[93,94]$ ) and GSK3, which in budding yeast is involved in meiotic induction and in heat stress tolerance [95].

\section{STE family}

All the STE kinases (a family including many kinases functioning in MAP kinase cascades) of $S$. cerevisiae and $S$. pombe were found to share homology relationships (Table 3, Fig. 5, Additional file 5), but no kinases of the STE family were found in E. cuniculi. The presence of putative MAPKKK-MAPKK-MAPK modules in the kinomes of the three Trypanosomatid species [19] suggests that these are likely to have been lost in a number of reduced kinomes such as those of P. falciparum [17], other Apicomplexa (Miranda-Saavedra, D. et al, submitted) and E. cuniculi. However, a number of key STE family members function in pathways distinct from MAP kinase pathways in the yeasts, for example Cdc15p/Cdc7 (discussed above), which forms part of the MEN/SIN late mitotic network. Some STE20 family members, such as budding yeast Ste20p itself, function upstream of MAP kinase pathways [89]. However, not all of their roles are mediated in this way and so it seems that these other roles are not required in E. cuniculi. Several of the STE kinases are Rho GTPaseactivated kinases (for example budding yeast Cla4p, Kic1p and Ste20p), characterised by a PB domain that binds the p21 GTPase and sometimes a PH domain upstream of this [96]. 

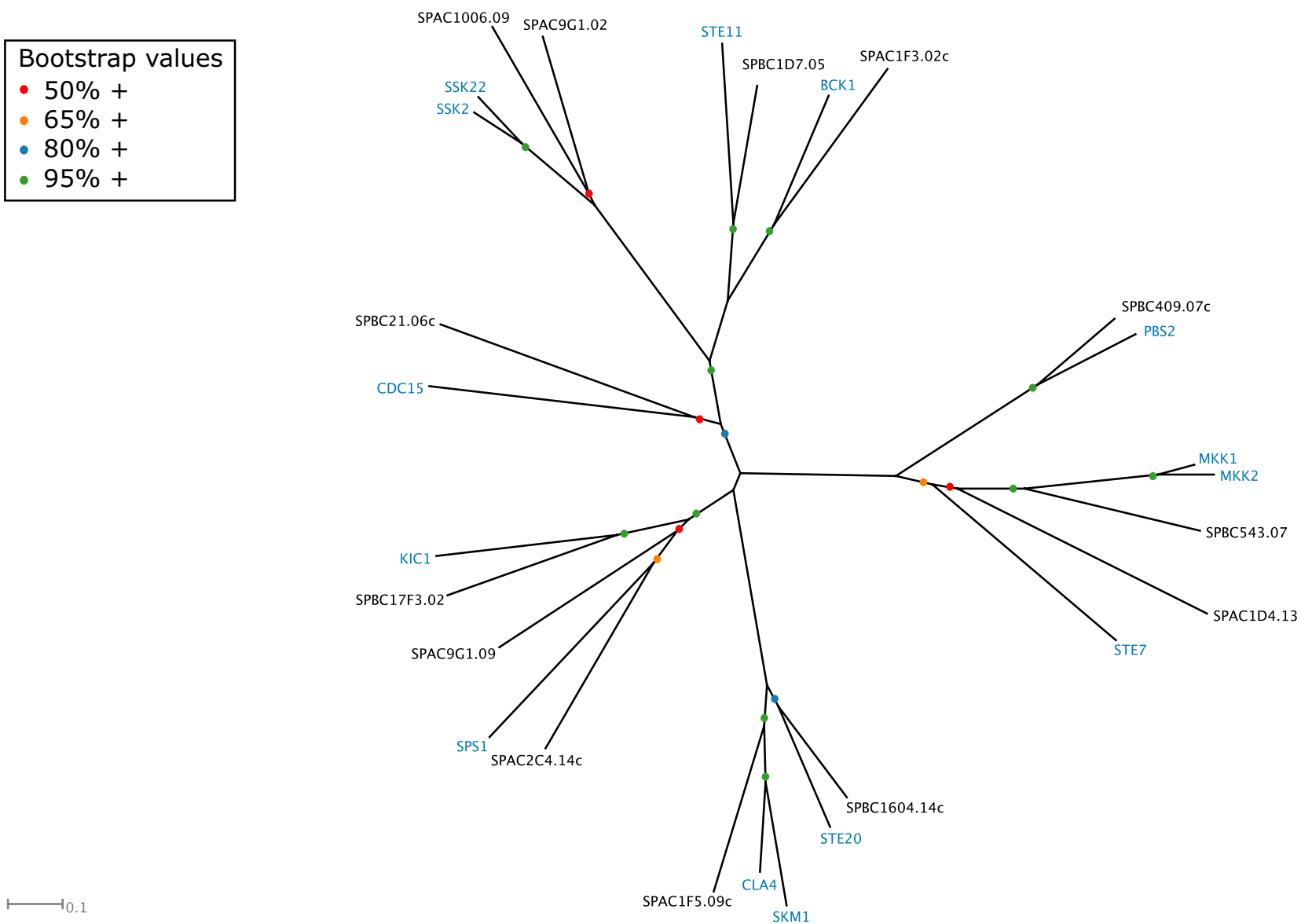

Figure 5

Unrooted tree of the STE kinases of S. cerevisiae (blue), S. pombe (black) and E. cuniculi (red).

\section{Other protein kinases (OPKs)}

This group is constituted by ePKs that cannot be classified confidently into any of the main ePK families. The multilevel HMM library has been used to classify some of the 'Other' kinases of $S$. cerevisiae into the main ePK families by comparison with syntenic homologous genes of the related fungus Ashbya gossypii [12]. However, some of the 'Other' kinases of $S$. cerevisiae are likely to constitute yeastspecific families in their own right, and whose identity will emerge upon examination of a larger number of fungal kinomes. Of the 5 microsporidian kinases included in the 'Other' group, only 3 could be mapped to homologous proteins in S. cerevisiae and S. pombe (Table 3, Fig. 6, Additional file 6). CAD25400.1 is the homologue of Bud32, which we have also now shown to be present in fission yeast. Although named for its apparent role in $S$. cerevisiae bud site selection [97], more recent studies have identified Bud32p kinase as a component of a conserved protein complex with important roles in transcription and telomere maintenance $[98,99]$, and it is likely that these roles explain its presence in E. cuniculi.

CAD24933.1 is the orthologue of the essential polo kinase (Cdc5p and Plo1 in S. cerevisiae and S. pombe, respectively), a conserved cell cycle regulatory kinase with many important roles in centrosome and spindle function, sister chromatid cohesion, kinetochore function and mitotic exit [100]. A key feature of Polo kinases is the presence of tandem Polo Box sequences (Pfam PF00659) in the C-terminal nonkinase domain, which like 14-3-3 proteins are a phosphopeptide binding domain that target the kinase to substrates phosphorylated by other kinases [100]. Although the E. cuniculi kinase lacks these characteristic Cterminal Polo boxes in a Pfam domain search, manual inspection of the C-terminal region provides evidence for two degenerate Polo box sequences, confirming the identity of this kinase as a Polo homologue. 


Bootstrap values
- $50 \%+$
- $65 \%+$
- $80 \%+$
- $95 \%+$

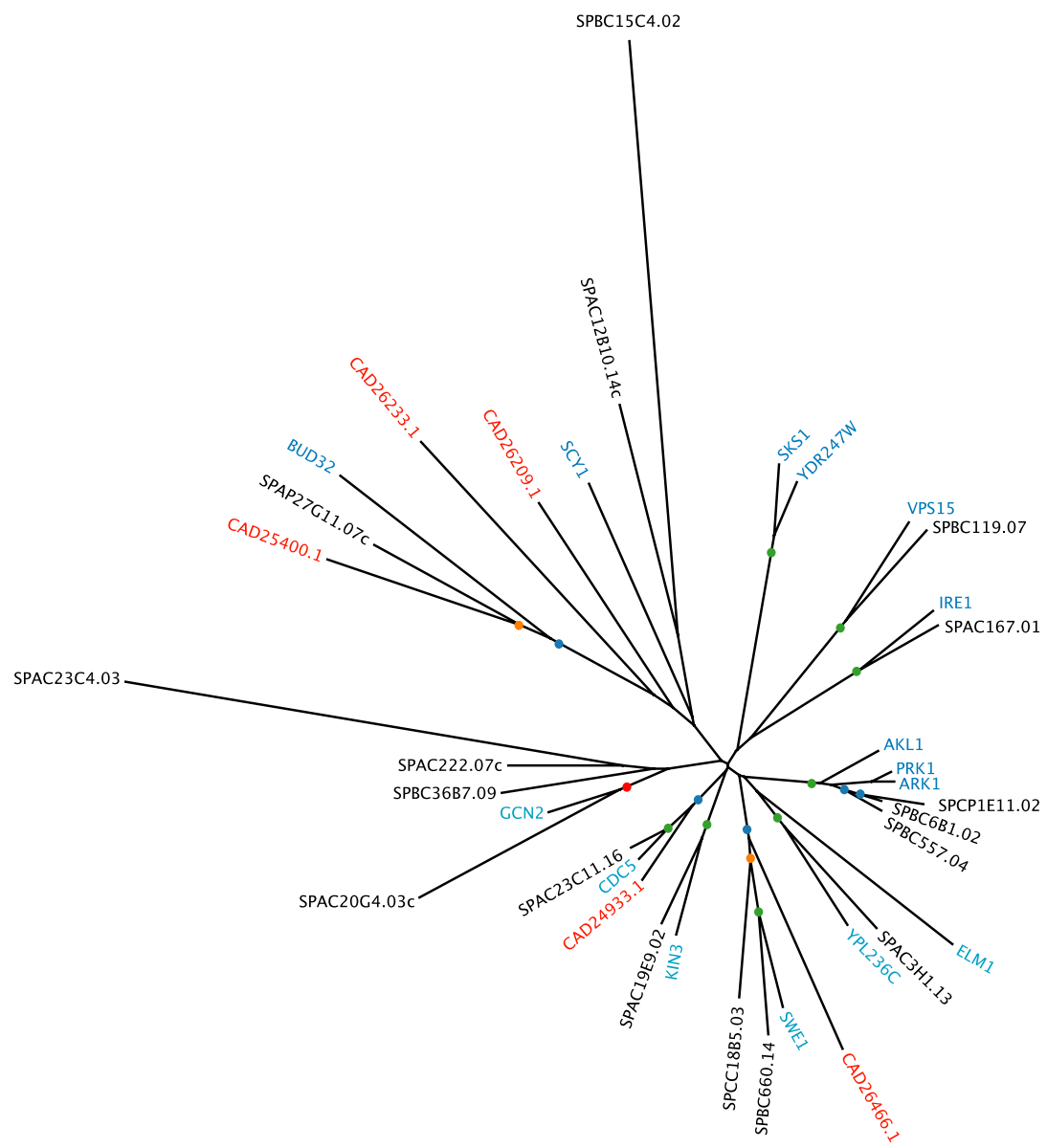

Figure 6

Unrooted tree of the 'Other' kinases of S. cerevisiae (blue), S. pombe (black) and E. cuniculi (red).

The third readily-assignable E. cuniculi kinase in the 'Other' group is an orthologue of budding yeast Swe1p and fission yeast Wee1 and Mik1 (Table 3). These kinases are negative regulators of the $\mathrm{Cdc} 28 \mathrm{p} / \mathrm{Cdc} 2 \mathrm{CDK}$ kinases that regulate the time of entry into mitosis [101-104]. This is an essential and critical role in fission yeast, where loss of both paralogous kinases causes catastrophic premature mitotic entry, whereas in budding yeast the effects of Swe1p are more subtle and cells can manage without it, at least under normal circumstances.

Protein kinases in the 'Other' group that are shared by the two model yeasts but that are not conserved in the microsporidian include Gcn2p (involved in amino acid sensing: [105]), Ire1p (required for the unfolded protein response: [106]), the Ark1p-related kinases required for regulating cortical actin function and endocytosis [107] and Vps15p (required for targeting proteins to the vacuole: [108]), and their fission yeast orthologues.

\section{Atypical protein kinases}

Only aPKs of the PIKK (phosphatidyl inositol 3' kinaserelated kinases) and RIO ('right open reading frame') families were identified in the E. cuniculi genome, and putative homology could be assigned in all three cases. CAD25142.1 and CAD25955.1 are related to budding yeast Tel1p and are likely to be involved in telomere maintenance and the DNA damage checkpoint response as discussed above. The TOR group of PIKK members are involved in nutrient sensing pathways and are not represented in the microsporidian [109]. A homologue of Tra1p, apparently conserved between the two yeast species, was also not evident despite its essential role as a core component of the SAGA and NuA4 histone acetyl transferase complexes in budding yeast that are important for transcriptional activation, particularly involving acidic activators [110,111]. It is not clear how E. cuniculi can dispense with such a function, although many (but not all) of the components of the yeast SAGA and NuA4 com- 
plexes are not essential for viability (see [25]). The Rio kinases are required for $20 \mathrm{~S}$ prerRNA processing $[112,113]$, a role which is apparently conserved in $E$. cuniculi. Finally, E. cuniculi lacks a pyruvate dehydrogenase (PDH) kinase, an enzyme that downregulates PDH activity by phosphorylation of the E1 subunit [114]. The status of PDH in E. cuniculi is currently somewhat equivocal, since the microsporidian has two E1 subunit homologues but no evident E2 or E3 component [115], and the E2 component is critical for regulating PDH kinase activity [116]. Thus without a complete PDH complex there is probably no need for a PDH kinase. With the exception of one of its two PDH kinases, budding yeast aPKs all show clear orthologous relationships to their fission yeast counterparts.

\section{Protein kinase accessory domains}

Only 2 ePKs belonging to the AGC family were found to contain readily identifiable domains in addition to the kinase catalytic domain. These are the protein kinase Cterminal domain (PF00433) and the protein kinase C phorbol ester/diacylglycerolbinding domain (PF00130). The microsporidian PKA (CAD25584.1) presents the domain architecture $\mathrm{NH}_{3}{ }^{+}$-kinase-PF00433- $\mathrm{CO}_{2}$ - The protein kinase C-terminal domain is found in a variety of proteins with different functions and dependencies, and so per se it is not useful for assigning putative function. The AGC kinase CAD25005.1 presents the domain organisation $\mathrm{NH}_{3}{ }^{+}$kinasePF00433PF00130- $\mathrm{CO}_{2}$.

\section{Protein kinase-regulating proteins}

Only two cyclins were found in the E. cuniculi genome (CAD26331.1 [Q8SRF2] and CAD27077.1 [Q8STR3]). One instance of the regulatory subunit of Casein Kinase II was also found (CAD25839.1 [Q8SR24]), plus two regulatory subunits of PKA (CAD24891.1 and CAD25013.1).

\section{Conclusion}

The 2.9 Mb genome of the microsporidian E. cuniculi is the smallest known for any eukaryote. A massive gene loss in the fungal clade, with additional elimination in $E$. cuniculi, has been inferred from the reconstruction of parsimonious evolutionary scenarios using either a subset of KOGs or "eukaryotic orthologous groups" [117] or the complete collection [118]. The common ancestor of $E$. cuniculi and two yeast species is predicted to contain 3,048 KOGs, and the branch leading to the microsporidian would be characterised by 586 gene gains and up to 1,969 gene losses. The E. cuniculi proteome appears as a package of compact proteins containing a significant proportion of orthologues with simplified domain organisation or with a high frequency of intragenic deletions [118]. From the analysis of the protein size distributions derived from sequenced genomes, it can be suggested that the lengthening of proteins in eukaryotes (non-parasitic species) allows for more complex regulation networks. Thus, protein shortening in E. cuniculi may reflect reduced proteinprotein interactions as a result of various gene losses linked to the intracellular parasitic nature [2]. The kinome of E. cuniculi, consisting of only 32 protein kinases (29 $\mathrm{ePKs}$ and $3 \mathrm{aPKs}$ ), is a good illustration of this hypothesis.

The microsporidian kinome is approximately one fourth the size of the kinomes of $S$. cerevisiae (115 ePKs and 9 aPKs) and $S$. pombe (109 ePKs and $8 \mathrm{aPKs}$ ). The E. cuniculi kinome has underscored the importance of a number of protein kinases that are involved in essential cellular processes and likely to be essential to all eukaryotes. Therefore, the microsporidian presents an opportunity for evaluating the basic aspects of the most fundamental cellular mechanisms as mediated by protein kinases. The E. cuniculi kinome includes what might be considered as a core set of protein kinases required for performing the cell division cycle: a Cdc28p/Cdc2 cyclin-dependent kinases to regulate progression through different cell cycle stages, its negative regulator (Swe1p/Wee1 orthologue), a DDK to trigger initiation of DNA replication, a polo kinase an Aurora kinase to orchestrate various aspects of cell division, a TTK for spindle pole duplication and homologues of Te1lp and Chk1p for regulation in response to DNA damage and/or stalled replication forks. A second CDK might also function as a CDK-activating kinase, and the Bud32p orthologue may be needed for telomere maintenance. Kinases involved specifically and fundamentally in cell cycle regulation may therefore represent $\sim 30 \%$ of the E. cuniculi kinome, and orthologues of all the critical activities appear to be present with the exception of those that form part of the fungal MEN/SIN pathways.

In contrast, E. cuniculi appears to lack almost all of the protein kinases involved in stress responses, ion homeostasis and nutrient signalling. Although it has orthologues of PKA and DYRK, there is a complete lack of MAP kinase pathways and many other kinases involved in these signalling routes. Most notable by their absence are TOR and AMPK, and E. cuniculi may be the first eukaryote in which neither of these conserved functions is found. These striking differences with other eukaryotes presumably relate to its specialised, intracellular, lifestyle as an obligate parasite. Within its parasitophorous vacuole, it can rely on the host cell to provide nutrients, ATP and an osmotically stabilized environment that must be relatively unchanging compared to that of the free-living yeasts. Since E. cuniculi is not thought to undergo meiosis, the absence of orthologues to the yeast meiotic kinases is also hardly surprising.

9/32 (28.1\%) of the microsporidian kinases are considered as 'semi-orphan' in our analysis, not showing clear orthologous relationships to any of the yeast kinases. This 
emphasizes the rapid evolution of some genes in $E$. cuniculi and these kinases may be involved in functions related to the parasitic lifestyle of the organism, for example the decision to initiate spore development (which is likely not to be nutrient-regulated as in yeasts), or regulation of the polar tube that is used for cell invasion [115]. In contrast, perhaps the most striking aspect of the comparison between the kinomes of $S$. cerevisiae and S. pombe is the extent to which orthologous relationships are clear: only $15 \%$ of kinases in each yeast could not be assigned such relationships despite at least 800 million years of divergent evolution [119]. We hope that the comparison between the kinomes of $S$. cerevisiae and $S$. pombe will stimulate research into many of the as yet uncharacterised fission yeast kinases.

\section{Methods Identification and classification of E. cuniculi protein kinases}

The set of predicted peptides of E. cuniculi was downloaded via the Sequence Retrieval System [120]. The set of 5003 predicted peptides of $S$. pombe was downloaded from the $S$. pombe Genome Project [121]. The retrieval of protein kinases and their automatic classification into protein kinase families was done by scanning the predicted peptides with a multi-level hidden Markov model library of the protein kinase superfamily run under HMMER v.2.1.1 [122,123]). This HMM library has been developed to identify and sub-classify protein kinase catalytic domains into one of the accepted conventional (ePK) and atypical (aPK) protein kinase families. The library has been shown to have a misclassification rate of zero on the family level and for the annotated kinomes of H. sapiens, M. musculus, C. elegans, S. cerevisiae, P. falciparum, and D. discoideum [12].

\section{Phylogenetic analysis}

Following the generation of multiple alignments for the kinase catalytic domains of each kinase family of $E$. cuniculi, S. cerevisiae, and S. pombe, these were inspected and curated for large insertions and misaligned regions. The final curated alignments were of a length of no less than 220 amino acids, in agreement with the size of the kinase catalytic domain ( 250 amino acids). SplitsTree [124] was used to generate the phylogenetic trees with the JTT matrix and the Neighbour-Joining algorithm. The bootstrap values reported here are based on 1000 replicates. Family-specific dendrograms derived from complete linkage clustering of kinase catalytic domains were eventually built to assist in the phylogenetic analysis.

\section{Identification of accessory domains, transmembrane helices, and protein kinase-regulating proteins}

The full-length protein kinases of E. cuniculi were scanned with a local installation of InterProScan $[125,126]$ run with default parameters. Transmembrane helices were predicted with TMHMM $2.0[127,128]$. Protein kinaseregulating subunits were identified with the Pfam HMMs (Pfam_fs versions) PF01214 (regulatory subunit of Casein Kinase II), PF00134 and PF02984 (cyclins), PF02197 (PKA regulatory subunit) and PF03941 (Sli15p).

\section{Abbreviations}

$\mathrm{ePK}$, conventional protein kinase; $\mathrm{aPK}$, atypical protein kinase; CDK, cyclin-dependent protein kinase; CDDK, Dbf4-dependent protein kinase; DYRK, dual specificity tyrosine phosphorylated and regulated kinase; HMM, hidden Markov model; KOGs, eukaryotic orthologous groups; MEN, mitotic exit network; PKA, cyclic AMPdependent protein kinase; SIN, septation initiation network.

\section{Authors' contributions}

CD and JCP carried out preliminary E. cuniculi database searches and phylogenetic analyses that initiated this study. DMS carried out the analysis presented here and wrote the larger part of the manuscript. CD, GJB, MJRS and CPV contributed to the writing of this manuscript. All authors read and approved the final manuscript.

\section{Additional material}

\section{Additional file 1}

Multiple sequence alignment of AGC family kinase catalytic domains from S. cerevisiae, S. pombe and E. cuniculi prior to curation for phylogenetic analysis.

Click here for file

[http://www.biomedcentral.com/content/supplementary/1471-

2164-8-309-S1.eps]

\section{Additional file 2}

Multiple sequence alignment of CAMK family kinase catalytic domains from S. cerevisiae, S. pombe and E. cuniculi prior to curation for phylogenetic analysis.

Click here for file

[http://www.biomedcentral.com/content/supplementary/1471-

2164-8-309-S2.eps]

\section{Additional file 3}

Multiple sequence alignment of CK1 family kinase catalytic domains from S. cerevisiae, S. pombe and E. cuniculi prior to curation for phylogenetic analysis.

Click here for file

[http://www.biomedcentral.com/content/supplementary/14712164-8-309-S3.eps] 


\section{Additional file 4}

Multiple sequence alignment of CMGC family kinase catalytic domains from S. cerevisiae, S. pombe and E. cuniculi prior to curation for phylogenetic analysis.

Click here for file

[http://www.biomedcentral.com/content/supplementary/1471-

2164-8-309-S4.eps]

\section{Additional file 5}

Multiple sequence alignment of STE family kinase catalytic domains from S. cerevisiae, S. pombe and E. cuniculi prior to curation for phylogenetic analysis.

Click here for file

[http://www.biomedcentral.com/content/supplementary/14712164-8-309-S5.eps]

\section{Additional file 6}

Multiple sequence alignment of Other family kinase catalytic domains from S. cerevisiae, S. pombe and E. cuniculi prior to curation for phylogenetic analysis

Click here for file

[http://www.biomedcentral.com/content/supplementary/14712164-8-309-S6.eps]

\section{Acknowledgements}

The authors thank Drs. Jonathan Monk and Tom Walsh for computer assistance. The authors also wish to thank the reviewers for their insightful comments. DMS was a 4-year Wellcome Trust Prize Studentship recipient at the University of Dundee.

\section{References}

I. Wittner M, Weiss LM: The Microsporidia and Microsporidiosis. Washington DC , American Society of Microbiology; 1999.

2. Katinka MD, Duprat S, Cornillot E, Metenier G, Thomarat F, Prensier G, Barbe V, Peyretaillade E, Brottier P, Wincker P, Delbac F, El Alaoui H, Peyret P, Saurin W, Gouy M, Weissenbach J, Vivares CP: Genome sequence and gene compaction of the eukaryote parasite Encephalitozoon cuniculi. Nature 200I, 4 I 4(6862):450-453.

3. Vivares $\mathrm{CP}$, Gouy M, Thomarat F, Metenier G: Functional and evolutionary analysis of a eukaryotic parasitic genome. Curr Opin Microbiol 2002, 5(5):499-505.

4. Cohen P: The origins of protein phosphorylation. Nat Cell Biol 2002, 4(5): EI $27-30$.

5. Cohen P: The regulation of protein function by multisite phosphorylation--a $\mathbf{2 5}$ year update. Trends Biochem Sci 2000, 25(I2):596-60I.

6. Cohen P: Protein kinases - the major drug targets of the twenty-first century? Nat Rev Drug Discov 2002, I (4):309-3 I5.

7. Scapin G: Protein kinase inhibition: different approaches to selective inhibitor design. Curr Drug Targets 2006, 7(II): 1443-1454.

8. Kaelin WG Jr.: Gleevec: prototype or outlier? SCi STKE 2004, 2004(225):pel 2.

9. Comis RL: The current situation: erlotinib (Tarceva) and gefitinib (Iressa) in non-small cell lung cancer. Oncologist 2005, I0(7):467-470.

10. Hanks SK, Hunter T: Protein kinases 6. The eukaryotic protein kinase superfamily: kinase (catalytic) domain structure and classification. Faseb J 1995, 9(8):576-596.

II. Manning G, Whyte DB, Martinez R, Hunter T, Sudarsanam S: The protein kinase complement of the human genome. Science 2002, 298(5600):1912-1934.

12. Miranda-Saavedra D and Barton, GJ: Classification and Functional Annotation of Eukaryotic Protein Kinases. PROTEINS 2007, 68(4):893-914.
13. Angermayr M, Bandlow $\mathrm{W}$ : The type of basal promoter determines the regulated or constitutive mode of transcription in the common control region of the yeast gene pair GCYII RIOI. J Biol Chem 1997, 272(50):31630-31635.

14. Doerig C, Meijer L: Antimalarial drug discovery: targeting protein kinases. Expert Opin Ther Targets 2007, I I(3):279-290.

15. Doerig C, Billker O, Pratt D, Endicott J: Protein kinases as targets for antimalarial intervention: Kinomics, structure-based design, transmission-blockade, and targeting host cell enzymes. Biochim Biophys Acta 2005, I754(I-2): 132-150.

16. Naula C, Parsons M, Mottram JC: Protein kinases as drug targets in trypanosomes and Leishmania. Biochim Biophys Acta 2005, 1754(1-2): I5I-159.

17. Ward P, Equinet L, Packer J, Doerig C: Protein kinases of the human malaria parasite Plasmodium falciparum: the kinome of a divergent eukaryote. BMC Genomics 2004, 5(I):79.

18. Anamika, Srinivasan N, Krupa A: A genomic perspective of protein kinases in Plasmodium falciparum. Proteins 2005, 58(I): $180-189$.

19. Parsons M, Worthey EA, Ward PN, Mottram JC: Comparative analysis of the kinomes of three pathogenic trypanosomatids: Leishmania major, Trypanosoma brucei and Trypanosoma cruzi. BMC Genomics 2005, 6:127.

20. Bimbo A, Jia Y, Poh SL, Karuturi RK, den Elzen N, Peng X, Zheng L, O'Connell M, Liu ET, Balasubramanian MK, Liu J: Systematic deletion analysis of fission yeast protein kinases. Eukaryot Cell 2005, 4(4):799-8।3.

21. Hunter T, Plowman GD: The protein kinases of budding yeast: six score and more. Trends Biochem Sci 1997, 22(I): 18-22.

22. Boudeau J, Miranda-Saavedra D, Barton GJ, Alessi DR: Emerging roles of pseudokinases. Trends Cell Biol 2006, I6(9):443-452.

23. KinBase: [http://www.kinase.com].

24. Weng S, Dong Q, Balakrishnan R, Christie K, Costanzo M, Dolinski $K$, Dwight SS, Engel S, Fisk DG, Hong E, Issel-Tarver L, Sethuraman A, Theesfeld C, Andrada R, Binkley G, Lane C, Schroeder M, Botstein D, Michael Cherry J: Saccharomyces Genome Database (SGD) provides biochemical and structural information for budding yeast proteins. Nucleic Acids Res 2003, 31 (I):216-218.

25. Saccharomyces.Genome.Database: [http://www.yeastgenome.org].

26. Pombase: [http://www.genedb.org/genedb/pombe].

27. Equinet $L$, Bapteste $E$, Thellier M, Ouarzane-Amara M, Vivares $C P$, Desportes-Livage I, Doerig C: The genes encoding CAMP. dependent protein kinase catalytic subunit homologues of the microsporidia Encephalitozoon intestinalis and $E$. cuniculi: molecular characterisation and phylogenetic analysis. Parasitol Int 2004, 53(4):277-285.

28. Hatanaka M, Shimoda C: The cyclic AMP/PKA signal pathway is required for initiation of spore germination in Schizosaccharomyces pombe. Yeast 200I, 18(3):207-217.

29. Stark MJR: Protein phosphorylation and dephosphorylation. In The Metabolism and Molecular Physiology of Saccharomyces cerevisiae 2nd edition. Edited by: Dickinson JR, Schweizer M. London , CRC Press; 2004:284-375.

30. Welton RM, Hoffman CS: Glucose monitoring in fission yeast via the $\mathbf{G p a 2} \mathbf{G} \alpha$, the $\mathbf{G i t 5} \mathbf{G} \beta$ and the Git3 putative glucose receptor. Genetics 2000, I 56(2):5।3-52I.

31. Toda T, Cameron S, Sass P, Zoller M, Wigler M: Three different genes in $S$. cerevisiae encode the catalytic subunits of the cAMP-dependent protein kinase. Cell 1987, 50(2):277-287.

32. Tanaka TU, Rachidi N, Janke C, Pereira G, Galova M, Schiebel E, Stark M], Nasmyth K: Evidence that the IpII-Sli 5 (Aurora kinaseINCENP) complex promotes chromosome bi-orientation by altering kinetochore-spindle pole connections. Cell 2002, I08(3):317-329.

33. Tanaka TU, Stark MJ, Tanaka K: Kinetochore capture and bi-orientation on the mitotic spindle. Nat Rev Mol Cell Biol 2005, 6(I 2):929-942.

34. Andrews PD, Knatko E, Moore WJ, Swedlow JR: Mitotic mechanics: the auroras come into view. Curr Opin Cell Biol 2003, I5(6):672-683.

35. Buvelot $S$, Tatsutani SY, Vermaak D, Biggins $S$ : The budding yeast IpII/Aurora protein kinase regulates mitotic spindle disassembly. J Cell Biol 2003, 160(3):329-339.

36. Leverson JD, Huang HK, Forsburg SL, Hunter T: The Schizosaccharomyces pombe aurora-related kinase Arkl interacts with the inner centromere protein Picl and mediates chro- 
mosome segregation and cytokinesis. Mol Biol Cell 2002, |3(4): | |32-| | 43.

37. Petersen J, Hagan IM: S. pombe aurora kinase/survivin is required for chromosome condensation and the spindle checkpoint attachment response. Curr Biol 2003, I3(7):590-597.

38. Toyn $\mathrm{JH}$, Araki $\mathrm{H}$, Sugino $\mathrm{A}$, Johnston $\mathrm{LH}$ : The cell-cycle-regulated budding yeast gene DBF2, encoding a putative protein kinase, has a homologue that is not under cell-cycle control. Gene 1991, 104(1):63-70.

39. Bardin AJ, Amon A: Men and sin: what's the difference? Nat Rev Mol Cell Biol 200I, 2(I I):8I5-826.

40. Simanis $\mathrm{V}$ : Events at the end of mitosis in the budding and fission yeasts. J Cell Sci 2003, I I 6(Pt 2I):4263-4275.

4I. Cueille N, Salimova E, Esteban V, Blanco M, Moreno S, Bueno A, Simanis V: FIpI, a fission yeast orthologue of the s. cerevisiae CDCI4 gene, is not required for cyclin degradation or rum I p stabilisation at the end of mitosis. J Cell Sci 200 I, I I 4(Pt 14):2649-2664.

42. Nelson B, Kurischko C, Horecka J, Mody M, Nair P, Pratt L, Zougman A, McBroom LD, Hughes TR, Boone C, Luca FC: RAM: a conserved signaling network that regulates Ace2p transcriptional activity and polarized morphogenesis. Mol Biol Cell 2003, I 4(9):3782-3803.

43. Kanai M, Kume K, Miyahara K, Sakai K, Nakamura K, Leonhard K, Wiley DJ, Verde F, Toda T, Hirata D: Fission yeast MO25 protein is localized at SPB and septum and is essential for cell morphogenesis. EMBO J 2005, 24(I 7):3012-3025.

44. Drgonova J, Drgon T, Tanaka K, Kollar R, Chen GC, Ford RA, Chan CS, Takai Y, Cabib E: Rholp, a yeast protein at the interface between cell polarization and morphogenesis. Science 1996, 272(5259):277-279.

45. Arellano M, Valdivieso MH, Calonge TM, Coll PM, Duran A, Perez P Schizosaccharomyces pombe protein kinase $C$ homologues, pcklp and pck2p, are targets of rhol $p$ and rho2p and differentially regulate cell integrity. J Cell Sci 1999, I I 2:3569-3578.

46. Schmitz HP, Lorberg A, Heinisch J]: Regulation of yeast protein kinase $C$ activity by interaction with the small GTPase Rholp through its amino-terminal HRI domain. Mol Microbiol 2002, 44(3):829-840.

47. Schmitz HP, Heinisch JJ, Schmitz HP, Lorberg A, Heinisch Jj: Evolution, biochemistry and genetics of protein kinase $C$ in fungi Regulation of yeast protein kinase $C$ activity by interaction with the small GTPase Rholp through its amino-terminal HRI domain. Curr Genet 2003, 43(4):245-254.

48. Heinisch JJ, Lorberg A, Schmitz HP, Jacoby JJ: The protein kinase C-mediated MAP kinase pathway involved in the maintenance of cellular integrity in Saccharomyces cerevisiae. Mol Microbiol 1999, 32(4):67 I-680.

49. Inagaki M, Schmelzle T, Yamaguchi K, Irie K, Hall MN, Matsumoto K PDKI homologs activate the Pkcl-mitogen-activated protein kinase pathway in yeast. Mol Cell Biol 1999 I 9(I 2):8344-8352.

50. Casamayor A, Torrance PD, Kobayashi T, Thorner J, Alessi DR Functional counterparts of mammalian protein kinases PDKI and SGK in budding yeast. Curr Biol I999, 9(4): I 86-197.

5I. Meraldi P, Draviam VM, Sorger PK: Timing and checkpoints in the regulation of mitotic progression. Dev Cell 2004, 7(I):45-60.

52. Iwanaga Y, Chi YH, Miyazato A, Sheleg S, Haller K, Peloponese JM Jr., Li Y, Ward JM, Benezra R, Jeang KT: Heterozygous deletion of mitotic arrest-deficient protein I (MADI) increases the incidence of tumors in mice. Cancer Res 2007, 67(I): 160-166.

53. Levin DE, Hammond $\mathrm{Cl}$, Ralston RO, Bishop JM: Two yeast genes that encode unusual protein kinases. Proc Natl Acad Sci USA 1987, 84(17):6035-6039.

54. Levin DE, Bishop JM: A putative protein kinase gene (kin I+) is important for growth polarity in Schizosaccharomyces pombe. Proc Natl Acad Sci U S A 1990, 87(2 I):8272-8276.

55. Drewes G, Nurse P: The protein kinase kin I, the fission yeast orthologue of mammalian MARK/PAR-I, localises to new cell ends after mitosis and is important for bipolar growth. FEBS Lett 2003, 554(I-2):45-49.

56. Finger FP, Hughes TE, Novick P: Sec3p is a spatial landmark for polarized secretion in budding yeast. Cell 1998, 92(4):559-57|
57. Elbert M, Rossi G, Brennwald P: The yeast par-I homologs kin I and kin2 show genetic and physical interactions with components of the exocytic machinery. Mol Biol Cell 2005, 16(2):532-549.

58. Nyberg KA, Michelson RJ, Putnam CW, Weinert TA: Toward maintaining the genome: DNA damage and replication checkpoints. Annu Rev Genet 2002, 36:617-656.

59. Krylov DM, Nasmyth K, Koonin EV: Evolution of eukaryotic cell cycle regulation: stepwise addition of regulatory kinases and late advent of the CDKs. Curr Biol 2003, I3(2): I73-177.

60. Lopes M, Cotta-Ramusino C, Pellicioli A, Liberi G, Plevani P, Muzi-Falconi M, Newlon CS, Foiani M: The DNA replication checkpoint response stabilizes stalled replication forks. Nature 200I, 4 I 2(6846):557-56|

6I. Tercero JA, Diffley JF: Regulation of DNA replication fork progression through damaged DNA by the Mecl/Rad53 checkpoint. Nature 200I, 4I2(6846):553-557.

62. Zhao X, Chabes A, Domkin V, Thelander L, Rothstein R: The ribonucleotide reductase inhibitor $\mathrm{SmIl}$ is a new target of the Mecl/Rad53 kinase cascade during growth and in response to DNA damage. Embo J 200I, 20(13):3544-3553.

63. Zhao X, Georgieva B, Chabes A, Domkin V, Ippel JH, Schleucher J, Wijmenga S, Thelander L, Rothstein R: Mutational and structural analyses of the ribonucleotide reductase inhibitor Smll define its Rnrl interaction domain whose inactivation allows suppression of mecl and rad53 lethality. Mol Cell Biol 2000 , 20(23):9076-9083

64. Hardie DG, Hawley SA: AMP-activated protein kinase: the energy charge hypothesis revisited. Bioessays 200I, 23(12): III2-1119.

65. Carlson M: Glucose repression in yeast. Curr Opin Microbiol 1999 , 2(2):202-207.

66. Rutter J, Probst BL, McKnight SL: Coordinate regulation of sugar flux and translation by PAS kinase. Cell 2002, I I I(I): 17-28.

67. Weidner E, Findley AM, Dolgikh V, Sokolova J: Microsporidian biochemistry and physiology. In The Microsporidia and Microsporidiosis Edited by: Wittner M, Weiss LM. Washington DC , American Society of Microbiology; 1999:172-195.

68. Goossens A, de La Fuente N, Forment J, Serrano R, Portillo F: Regulation of yeast $\mathrm{H+}$-ATPase by protein kinases belonging to a family dedicated to activation of plasma membrane transporters. Mol Cell Biol 2000, 20(20):7654-766I.

69. Okuzaki D, Watanabe T, Tanaka S, Nojima H: The Saccharomyces cerevisiae bud-neck proteins Kcc4 and Gin4 have distinct but partially-overlapping cellular functions. Genes Genet Syst 2003 78(2): I | 3-126.

70. Kanoh J, Russell P: The protein kinase Cdr2, related to Nim I/ Cdrl mitotic inducer, regulates the onset of mitosis in fission yeast. Mol Biol Cell 1998, 9(12):332 I-3334.

7I. Babu P, Deschenes RJ, Robinson LC: Akrlp-dependent palmitoylation of Yck2p yeast casein kinase $I$ is necessary and sufficient for plasma membrane targeting. J Biol Chem 2004, 279(26):27|38-27|47.

72. Feng Y, Davis NG: Akr I p and the type I casein kinases act prior to the ubiquitination step of yeast endocytosis: Akrlp is required for kinase localization to the plasma membrane. Mol Cell Biol 2000, 20(I 4):5350-5359.

73. Robinson LC, Menold MM, Garrett S, Culbertson MR: Casein kinase I-like protein kinases encoded by YCKI and YCK2 are required for yeast morphogenesis. Mol Cell Biol 1993, 13(5):2870-288|

74. Dhillon N, Hoekstra MF: Characterization of two protein kinases from Schizosaccharomyces pombe involved in the regulation of DNA repair. EMBO I 1994, I3( I 2):2777-2788.

75. Knippschild U, Gocht A, Wolff S, Huber N, Lohler J, Stoter M: The casein kinase I family: participation in multiple cellular processes in eukaryotes. Cell Signal 2005, 17(6):675-689.

76. Petronczki M, Matos J, Mori S, Gregan J, Bogdanova A, Schwickart M, Mechtler K, Shirahige K, Zachariae W, Nasmyth K: Monopolar attachment of sister kinetochores at meiosis I requires casein kinase I. Cell 2006, I 26(6): 1049-1064.

77. Kafadar KA, Zhu H, Snyder M, Cyert MS: Negative regulation of calcineurin signaling by Hrr25p, a yeast homolog of casein kinase I. Genes Dev 2003, I 7(2I):2698-2708.

78. Diffley JF, Labib K: The chromosome replication cycle. J Cell Sci 2002, II 5(Pt 5):869-872. 
79. Kaldis $P$, Sutton A, Solomon MJ: The Cdk-activating kinase (CAK) from budding yeast. Cell 1996, 86(4):553-564.

80. Hermand $D$, Westerling $T$, Pihlak A, Thuret JY, Vallenius $T$, Tiainen M, Vandenhaute J, Cottarel G, Mann C, Makela TP: Specificity of Cdk activation in vivo by the two Caks Mcs6 and Csk I in fission yeast. $E M B O J$ 200I, 20(I-2):82-90.

8I. Fisk HA, Mattison CP, Winey M: A field guide to the Mps I family of protein kinases. Cell Cycle 2004, 3(4):439-442.

82. Fisk HA, Mattison CP, Winey M: Human Mps I protein kinase is required for centrosome duplication and normal mitotic progression. Proc Natl Acad Sci USA 2003, I00(25): I 4875-I 4880.

83. He X, Jones MH, Winey M, Sazer S: Mph I, a member of the Mpsl-like family of dual specificity protein kinases, is required for the spindle checkpoint in $\mathrm{S}$. pombe. J Cell Sci 1998, III:1635-1647.

84. Moriya H, Shimizu-Yoshida Y, Omori A, Iwashita S, Katoh M, Sakai A: Yaklp, a DYRK family kinase, translocates to the nucleus and phosphorylates yeast Pop2p in response to a glucose signal. Genes Dev 200I, I 5(10): I217-1228.

85. Garrett S, Broach J: Loss of Ras activity in Saccharomyces cerevisiae is suppressed by disruptions of a new kinase gene, YAKI, whose product may act downstream of the CAMP. dependent protein kinase. Genes Dev 1989, 3(9): I336-1348.

86. Garrett S, Menold MM, Broach JR: The Saccharomyces cerevisiae YAKI gene encodes a protein kinase that is induced by arrest early in the cell cycle. Mol Cell Biol I99 I, I I (8):4045-4052.

87. Snell V, Nurse P: Genetic analysis of cell morphogenesis in fission yeast - a role for casein kinase II in the establishment of polarized growth. EMBO J 1994, I3(9):2066-2074.

88. Poole A, Poore T, Bandhakavi S, McCann RO, Hanna DE, Glover CV: A global view of CK2 function and regulation. Mol Cell Biochem 2005, 274(I-2): 163-170.

89. Qi M, Elion EA: MAP kinase pathways. J Cell Sci 2005, I I 8(Pt 16):3569-3572.

90. Smith DA, Toone WM, Chen D, Bahler J, Jones N, Morgan BA, Quinn J: The Srk I protein kinase is a target for the Sty I stress-activated MAPK in fission yeast. I Biol Chem 2002, 277(36):334II-3342I.

91. Toda T, Dhut S, Superti-Furga G, Gotoh Y, Nishida E, Sugiura R, Kuno $\mathrm{T}$ : The fission yeast pmkl+ gene encodes a novel mitogenactivated protein kinase homolog which regulates cell integrity and functions coordinately with the protein kinase $\mathrm{C}$ pathway. Mol Cell Biol 1996, I6(I 2):6752-6764.

92. Neiman AM, Stevenson BJ, Xu HP, Sprague GF Jr., Herskowitz I, Wigler M, Marcus S: Functional homology of protein kinases required for sexual differentiation in Schizosaccharomyces pombe and Saccharomyces cerevisiae suggests a conserved signal transduction module in eukaryotic organisms. Mol Biol Cell 1993, 4(I): 107-120.

93. Abe H, Shimoda C: Autoregulated expression of Schizosaccharomyces pombe meiosis-specific transcription factor Mei4 and a genome-wide search for its target genes. Genetics 2000, I 54(4): | 497-I 508.

94. Schindler K, Winter E: Phosphorylation of Ime2 regulates meiotic progression in Saccharomyces cerevisiae. I Biol Chem 2006, 28 I(27): |8307-18316.

95. Kassir Y, Rubin-Bejerano I, Mandel-Gutfreund Y: The Saccharomyces cerevisiae GSK-3 beta homologs. Curr Drug Targets 2006 7(II): 1455-| 465 .

96. Wild AC, Yu JW, Lemmon MA, Blumer KJ: The p2I-activated protein kinase-related kinase $\mathrm{Cla} 4$ is a coincidence detector of signaling by $\mathrm{Cdc42}$ and phosphatidylinositol 4-phosphate. J Biol Chem 2004, 279( I 7): 17101-171 I0.

97. Ni L, Snyder M: A genomic study of the bipolar bud site selection pattern in Saccharomyces cerevisiae. Mol Biol Cell 200I, I 2(7):2147-2170.

98. Downey M, Houlsworth R, Maringele L, Rollie A, Brehme M, Galicia S, Guillard S, Partington M, Zubko MK, Krogan NJ, Emili A, Greenblatt JF, Harrington L, Lydall D, Durocher D: A genome-wide screen identifies the evolutionarily conserved KEOPS complex as a telomere regulator. Cell 2006, I 24(6): I | 155-| I68.

99. Kisseleva-Romanova E, Lopreiato R, Baudin-Baillieu A, Rousselle JC Ilan L, Hofmann K, Namane A, Mann C, Libri D: Yeast homolog of a cancer-testis antigen defines a new transcription complex. $E M B O$ / 2006, 25( ( 5):3576-3585
100. Barr FA, Sillje HH, Nigg EA: Polo-like kinases and the orchestration of cell division. Nat Rev Mol Cell Biol 2004, 5(6):429-440.

10I. Hu F, Aparicio OM: Swel regulation and transcriptional control restrict the activity of mitotic cyclins toward replication proteins in Saccharomyces cerevisiae. Proc Natl Acad Sci USA 2005, I02(25):8910-8915

102. Lew DJ: The morphogenesis checkpoint: how yeast cells watch their figures. Curr Opin Cell Biol 2003, I 5(6):648-653.

103. Lundgren K, Walworth N, Booher R, Dembski M, Kirschner M, Beach $D$ : mik I and weel cooperate in the inhibitory tyrosine phosphorylation of cdc2. Cell I99I, 64(6): I III-II22.

104. Rhind N, Russell P: Tyrosine phosphorylation of Cdc2 is required for the replication checkpoint in Schizosaccharomyces pombe. Mol Cell Biol 1998, I8(7):3782-3787.

105. Dever TE, Feng L, Wek RC, Cigan AM, Donahue TF, Hinnebusch AG: Phosphorylation of initiation factor 2 alpha by protein kinase GCN2 mediates gene-specific translational control of GCN4 in yeast. Cell 1992, 68(3):585-596.

106. Urano F, Bertolotti A, Ron D: IREI and efferent signaling from the endoplasmic reticulum. / Cell Sci 2000, I I 3:3697-3702.

107. Smythe $E$, Ayscough KR: The ArkI/PrkI family of protein kinases. Regulators of endocytosis and the actin skeleton. EMBO Rep 2003, 4(3):246-25।.

108. Stack JH, Herman PK, Schu PV, Emr SD: A membrane-associated complex containing the $\mathrm{Vps} / 5$ protein kinase and the $\mathrm{Vps} 34$ PI 3-kinase is essential for protein sorting to the yeast lysosome-like vacuole. EMBO J 1993, I 2(5):2 195-2204.

109. Wullschleger S, Loewith $R$, Hall MN: TOR signaling in growth and metabolism. Cell 2006, 124(3):47|-484.

110. Grant PA, Schieltz D, Pray-Grant MG, Yates JR 3rd, Workman JL: The ATM-related cofactor Tral is a component of the purified SAGA complex. Mol Cell 1998, 2(6):863-867.

III. Brown CE, Howe L, Sousa K, Alley SC, Carrozza MJ, Tan S, Workman JL: Recruitment of HAT complexes by direct activator interactions with the ATM-related Tral subunit. Science 200I, 292(5525):2333-2337.

I 2. Vanrobays E, Gelugne JP, Gleizes PE, Caizergues-Ferrer M: Late cytoplasmic maturation of the small ribosomal subunit requires RIO proteins in Saccharomyces cerevisiae. Mol Cell Biol 2003, 23(6):2083-2095.

113. LaRonde-LeBlanc N, Wlodawer A: The RIO kinases: an atypical protein kinase family required for ribosome biogenesis and cell cycle progression. Biochim Biophys Acta 2005, I754(I2): $14-24$.

114. Roche TE, Baker JC, Yan X, Hiromasa Y, Gong X, Peng T, Dong J, Turkan A, Kasten SA: Distinct regulatory properties of pyruvate dehydrogenase kinase and phosphatase isoforms. Prog Nucleic Acid Res Mol Biol 200I, 70:33-75.

II5. Vivares CP, Metenier G: The microsporidian Encephalitozoon. Bioessays 2001, 23(2): 194-202.

I16. Tuganova A, Popov KM: Role of protein-protein interactions in the regulation of pyruvate dehydrogenase kinase activity. Biochem I 2005, 387(Pt I): | 47-I53.

117. Tatusov RL, Fedorova ND, Jackson JD, Jacobs AR, Kiryutin B, Koonin EV, Krylov DM, Mazumder R, Mekhedov SL, Nikolskaya AN, Rao BS, Smirnov S, Sverdlov AV, Vasudevan S, Wolf YI, Yin J], Natale DA: The COG database: an updated version includes eukaryotes. BMC Bioinformatics 2003, 4:4I.

118. Koonin EV, Fedorova ND, Jackson JD, Jacobs AR, Krylov DM, Makarova KS, Mazumder R, Mekhedov SL, Nikolskaya AN, Rao BS, Rogozin IB, Smirnov S, Sorokin AV, Sverdlov AV, Vasudevan S, Wolf YI, Yin IJ, Natale DA: A comprehensive evolutionary classification of proteins encoded in complete eukaryotic genomes. Genome Biol 2004, 5(2):R7.

119. Krylov DM, Wolf YI, Rogozin IB, Koonin EV: Gene loss, protein sequence divergence, gene dispensability, expression level, and interactivity are correlated in eukaryotic evolution. Genome Res 2003, I 3( I 0):2229-2235.

120. Zdobnov EM, Lopez R, Apweiler R, Etzold T: The EBI SRS servernew features. Bioinformatics 2002, 18(8): ||49-1| 50 .

121. S.pombe.Genome.Project: [http://www.sanger.ac.uk/Projects/ $S$ pombe/]

122. HMMER: [http://selab.janelia.org].

123. Eddy SR: Profile hidden Markov models. Bioinformatics 1998 , |4(9):755-763. 
124. Huson DH: SplitsTree: analyzing and visualizing evolutionary data. Bioinformatics 1998, I4(I):68-73.

125. Quevillon E, Silventoinen V, Pillai S, Harte N, Mulder N, Apweiler R, Lopez R: InterProScan: protein domains identifier. Nucleic Acids Res 2005, 33(Web Server issue):WI 16-20.

126. Zdobnov EM, Apweiler R: InterProScan-an integration platform for the signature-recognition methods in InterPro. Bioinformatics 200I, I7(9):847-848.

127. Krogh A, Larsson B, von Heijne G, Sonnhammer EL: Predicting transmembrane protein topology with a hidden Markov model: application to complete genomes. J Mol Biol 200I, 305(3):567-580.

128. Sonnhammer EL, von Heijne G, Krogh A: A hidden Markov model for predicting transmembrane helices in protein sequences. Proc Int Conf Intell Syst Mol Biol 1998, 6:175-182.

Publish with Bio Med Central and every scientist can read your work free of charge

"BioMed Central will be the most significant development for disseminating the results of biomedical research in our lifetime. "

Sir Paul Nurse, Cancer Research UK

Your research papers will be:

- available free of charge to the entire biomedical community

- peer reviewed and published immediately upon acceptance

- cited in PubMed and archived on PubMed Central

- yours - you keep the copyright

Submit your manuscript here:

http://www.biomedcentral.com/info/publishing_adv.asp
BiolMedcentral 